Research Article

\title{
Estimation of Vehicle Carbon Emissions in China Accounting for Vertical Curve Effects
}

\author{
Yaping Dong and Jinliang Xu $(\mathbb{D}$ \\ School of Highway, Chang'an University, Xi'an 710064, China \\ Correspondence should be addressed to Jinliang Xu; xujinliang@chd.edu.cn
}

Received 13 April 2020; Revised 27 June 2020; Accepted 24 July 2020; Published 29 August 2020

Academic Editor: Mahmoud Mesbah

Copyright (C) 2020 Yaping Dong and Jinliang $\mathrm{Xu}$. This is an open access article distributed under the Creative Commons Attribution License, which permits unrestricted use, distribution, and reproduction in any medium, provided the original work is properly cited.

\begin{abstract}
Predicting vehicle carbon emissions on vertical curve sections can provide guidance for low-carbon vertical profile designs. Given that the influence of vertical curve design indicators on the fuel consumption and $\mathrm{CO}_{2}$ emissions of vehicles are underexplored, this study filled this research gap by establishing a theoretical carbon emission model of vehicles on vertical curve sections. The carbon emission model was established based on Xu's vehicle energy conversion model, the conversion model of energy, fuel consumption, and $\mathrm{CO}_{2}$ emissions. The accuracy of the theoretical carbon emission model and the $\mathrm{CO}_{2}$ emission rules on vertical curve sections were verified by field test results. Field tests were carried out on flat sections, longitudinal slope sections, and various types of vertical curve sections, with five common types of vehicles maintaining cruising speed. The carbon emission rate effects on the vertical curve are closely related to the gradient and irrelevant of the radius. On the vertical profile composed with downhill/ asymmetric/symmetrical vertical curve with a gradient greater than the balance gradient, the carbon emission rate is determined by the gradient and radius. The influence of the gradient on carbon emissions of vehicle on these vertical profiles was more significant than the radius. The radius is irrelevant to the carbon emission rate on the other forms of vertical profile. These results may benefit highway designers and engineers by providing guidelines regarding the environmental effects of highway vertical curve indexes.
\end{abstract}

\section{Introduction}

Global warming caused by $\mathrm{CO}_{2}$ emissions is an environmental issue of urgent public concern. The vertical curve is an important part of the vertical profile section of the highway and thus affects emission properties, such as carbon emissions, in motor vehicles. Previous research on fuel consumption and carbon emissions has centered on vehicle operating conditions [1-3] and vehicle power loads [4-6]. Studies have shown that vertical curve indicators have crucial effect on the carbon emitted by various vehicles $[1,4]$. Exploring the relationship between vertical curve design indexes and carbon emissions of vehicles is of great significance in guiding the low-carbon design of vertical profiles.

Scholars dedicated to quantifying vehicle carbon emissions have established various microcarbon emission models including the Mobile Source Emissions Factor Model (MOBILE) [7], Comprehensive Modal Emissions Model (CMEM) [5], International Vehicle Emissions Model (IVE) [2], and Motor Vehicle Emissions Simulator (MOVES) [3] to reflect the real-time operating conditions of vehicles. The databases for these models were established based on laboratory dynamometer tests. Among them, the MOVES, constructed by the United States Environmental Protection Agency, is the most authoritative. The specific power and instantaneous speed were selected to characterize the vehicle's actual operating conditions [3].

Fuel consumption is closely related to $\mathrm{CO}_{2}$ emissions. Several mechanical models have been proposed based on the dynamic load of vehicles [6, 8-10]. Chang and Morlok [6] established a fuel consumption model of passenger cars on longitudinal slope sections $[4,6]$. It should be noted that balance gradient divided two types of vehicle dynamic loads 
on downhill sections. The "balance gradient," gradient of downhill sections in which the gravity potential energy completely offsets air and rolling resistance, creates two distinct types of vehicle dynamic loads on downhill sections. When the road gradient exceeds the balance gradient, no driving energy is required to overcome rolling resistance and air resistance. However, the reverse mechanical resistance of the engine is not included in existing balance gradient calculations. Ehsani et al. [8] proposed a carbon emission model of vehicles on longitudinal slope sections in the presence of propulsion energy. Demir et al. [11] proposed that, in the absence of driving energy requirements, the fuel consumption of a vehicle is basically equal to its idling fuel consumption. $\mathrm{Xu}$ et al. $[9,10]$ established an energy conversion model of vehicles on flat road, uphill, and downhill sections in China and adopted the carbon emissions and energy conversion model proposed by the Intergovernmental Panel on Climate Change (IPCC) [12] to derive carbon emissions that are consistent with the current status of Chinese vehicles and fuel. The theoretical carbon emission model was evaluated using field test data to ensure the reliability of the model. Indeed, this model can be directly applied to estimate the carbon emissions of vehicles on vertical curve sections in China.

Table 1 shows a schematic comparison between existing models. Existing microcarbon emission models, such as MOVES, were established by using large sets of measurement data from laboratory dynamometer tests; simulation data do not directly reflect the carbon emissions of vehicles on real roads and has an insufficient theoretical basis. Simulation results can be successively obtained from the MOVES database to derive specific power, fuel, and carbon emission information. Different vehicle types and vehicle shapes, however, have been taken into consideration. Furthermore, the fuel efficiency determined by various engine types has not yet been studied. The default parameters in MOVES are based on current data from the United States. Relevant parameters such as vehicle fuel qualities and climatic conditions differ from those in China, so MOVES cannot be directly applied to the prediction of vehicle's carbon emissions on vertical curve sections in China $[13,14]$. Table 2 shows a comparison of maximum main fuel quality indicator values in 2019 between the United States and China. The vehicle carbon emission models based on the vehicle dynamics theory have a stronger theoretical basis than the microcarbon emission models. As shown in Table 1, the theoretical carbon emission model proposed by Xu et al. $[9,10]$ mitigates the deficiencies of other models by considering more comprehensive parameters. The model was also verified by a field experiment with a maximum error of $9.97 \%$. The theoretical carbon emission model of vehicles on longitudinal slope sections proposed by Xu et al. $[9,10]$ is thus more accurate than other models.

Considering that the radius affects the gradient of each position on the vertical curve $[1,4]$, a carbon emission model suited to vertical curve sections can generally be constructed by analyzing vehicle driving energy and carbon emission models under different slope conditions. Ko et al. [1] obtained the carbon emissions on a vertical curve section by simulating the carbon emission rate on specific gradients of separate positions of a vertical curve section using MOVES. Only a comparative analysis of fuel consumption and carbon emissions in the specific scenario of a symmetrical vertical curve with the $9 \%$ terminal slope at both ends was made. The results showed that the design vehicle, respectively, consumed and produced 10 percent less fuel and carbon dioxide on the vertical curve designed with 1.5 times greater than the minimum vertical curvature value recommended in the Green Book. Due to insufficient data, however, no quantitative model of vehicle's carbon emissions on vertical curve sections has been proposed. The influence of terminal gradients of the vertical curve on carbon emissions of vehicles also remains unclear. It is worth noting that a vehicle's carbon emissions appear to be closely related to the radius, curvature, and curve length. Based on the fuel consumption model on longitudinal slope sections proposed by Chang and Morlok [6], Kang et al. [4] proposed a computational method for evaluating fuel consumption of passenger cars on vertical curve sections by adding the fuel consumption on different gradients changing along the vehicle's path. The carbon emission model of vehicles on longitudinal slope sections proposed by $\mathrm{Xu}$ et al. $[9,10]$ provides a relatively reliable theoretical basis for establishing the carbon emission model of vehicles on vertical curve sections in China.

The purposes of the present study are to establish a carbon emission model of vehicles on vertical curves and to reveal the low-carbon design indexes of the vertical curve. The carbon emission model of vehicles on vertical curve sections were deduced based on Xu's $[9,10]$ vehicle energy conversion model and the IPCC conversion model [12]. Then, coupled with field tests for verification, the reliability of the theoretical model was guaranteed. To explore the influence of the vertical curve design indexes on $\mathrm{CO}_{2}$ emissions, the vehicle speed on the road vertical profile was assumed as uniform to mitigate the effects of speed fluctuations on the vehicle's carbon emissions.

The remainder of this paper is organized as follows: in Section 2, vehicle carbon emission model on vertical curves are deduced based on the vehicle energy conversion model proposed by Xu et al. $[9,10]$ and the IPCC conversion model [12]. The carbon emission rules on different forms of vertical curve are also revealed. Field test data collected to analyze carbon emission rules and validate the proposed model are also presented. Section 3 discusses the accuracy of the model and the influence of design indicators (gradient and radius) on vehicle carbon emissions on vertical curves and vertical profile sections. Section 4 provides a brief summary and conclusion.

\section{Methods}

The methodological process that was used in this study is shown in Figure 1. The basic approach used to establish the theoretical carbon emission model of vehicles on vertical curves was deductive. The derivation began with basic cases of a vehicle moving on a level, uphill, or downhill section under the vehicle energy conversion model proposed by $\mathrm{Xu}$ et al. $[9,10]$. The results for those cases were then generalized 


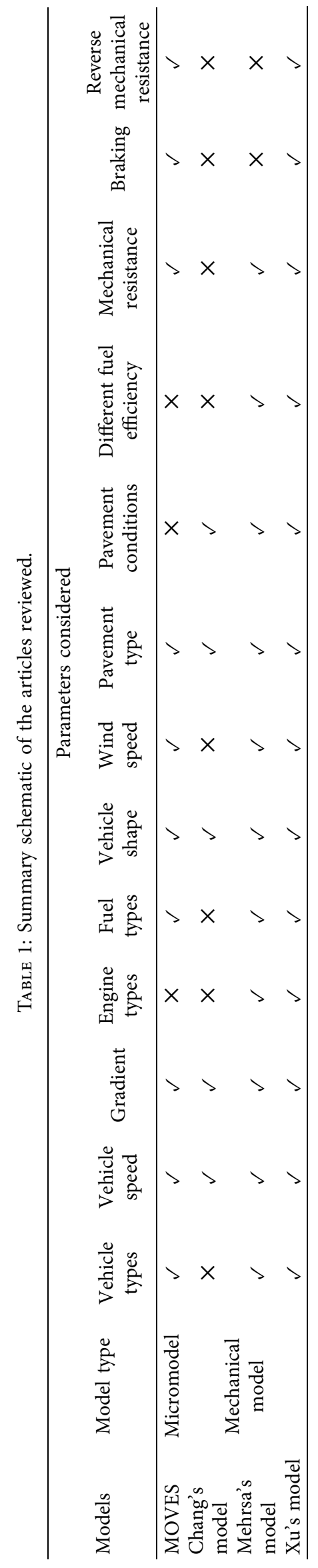


TABLE 2: Summary of fuel quality in United States and China.

\begin{tabular}{|c|c|c|c|c|c|c|c|c|}
\hline \multirow{2}{*}{ Fuel type } & \multirow{2}{*}{ Region } & \multicolumn{7}{|c|}{ Indicators specification } \\
\hline & & RVP (psi) & Sulfur (ppm) & Aromatic (\%) & Olefin (\%) & Benzene (\%) & T50 $\left({ }^{\circ} \mathrm{C}\right)$ & T90 $\left({ }^{\circ} \mathrm{C}\right)$ \\
\hline \multirow{2}{*}{ Gasoline } & USA & 6.9 & 30 & 26.1 & 5.6 & 1 & 218 & 329 \\
\hline & China & 12.33 & 10 & 40 & 24 & 1 & 120 & 190 \\
\hline \multirow{2}{*}{ Diesel } & USA & 7.614 & 10 & 40 & 24 & 1 & 248 & 374 \\
\hline & China & 12.763 & 10 & 35 & - & - & 355 & 365 \\
\hline
\end{tabular}

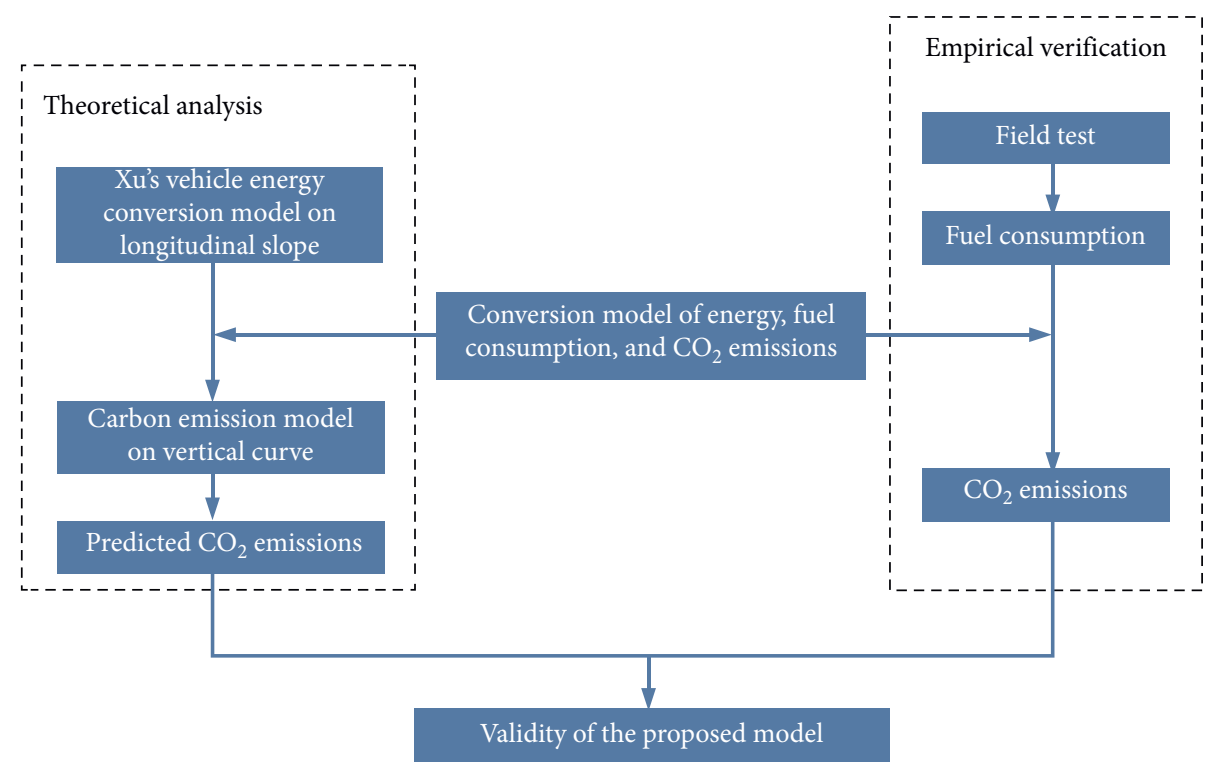

FIGURE 1: Flowchart of methods.

to various forms of vertical curve involving gradients, where the radius affects the gradient of each position on the curve. The energy, fuel consumption, and carbon emission conversion model were established according to factors such as China's vehicle characteristics and fuel characteristics. A field test was conducted to collect velocity and fuel consumption data. The carbon emission data were converted from the measured fuel consumption data using the Chinese fuel consumption and $\mathrm{CO}_{2}$ emission conversion model. Finally, the theoretical carbon emission model was evaluated using the field test data. This combination of theoretical analysis and empirical verification ensured the reliability of the conclusions presented here.

2.1. Vehicle Energy Conversion. The gentle slope of the vertical curve replaces the original steep gradient of the longitudinal slope. The carbon emissions of a vehicle on a vertical curve section are closely related to the slope of the vertical curve. Before establishing the energy conversion model on vertical curve sections, the energy conversion relationship of the vehicle on uphill and downhill sections must be clarified. According to numerous previous studies $[6,8,15]$, vehicles encounter different tractive force conditions on flat, uphill, and downhill sections. This was again confirmed recently by $\mathrm{Xu}$ et al. [9, 10]. The energy conversion formulas for different gradients of longitudinal slopes were derived from the law of conservation of mechanical energy and the theory of vehicle longitudinal dynamics. Thus, the vehicle propulsive energy necessary to overcome the total resistance on flat, uphill, and downhill sections was placed in the simplest form possible, as shown below.

Propulsive force is required for the vehicle on a level terrain for the purpose of maintaining a cruising speed as only rolling and air resistance act on the vehicle. A significantly higher propulsive force is required for driving on upgrade sections than flat sections owing to the grade impact (grade resistance). The vehicle propulsive energy necessary to overcome the total resistance on a flat section and an uphill section at the cruising speed are given in the simplest form as

$$
\begin{aligned}
& W=W_{a}+W_{r}, \\
& W=E_{g}+W_{a}+W_{r},
\end{aligned}
$$

where $W$ is the work done by the driving force $(\mathrm{N} \cdot \mathrm{m})$, as shown in equations (2) and (3), and $E_{g}, W_{a}$, and $W_{r}$ are the gravitational potential energy of the vehicle $(J)$, the work done by air resistance $(\mathrm{N} \cdot \mathrm{m})$, and the energy consumed by rolling resistance $(\mathrm{J})$, respectively, which can be approximated by equations (4)-(6) [16-19]:

$$
\begin{aligned}
& W=F S=\left(F_{i}-F_{t}\right) S=F_{i} n_{t f} S, \\
& W=W_{i} n_{t f},
\end{aligned}
$$




$$
\begin{aligned}
& E_{g}=m g S i, \\
& W_{a}=F_{a} S=\frac{1}{2} A C_{D} \rho V^{2} S, \\
& W_{r}=F_{r} S=S m g C_{r} \frac{\left(C_{1} v+C_{2}\right)}{1000},
\end{aligned}
$$

where $F$ is the effective driving force of the engine $(\mathrm{N})$, which is numerically equal to the total resistance of the vehicle. $W_{i}$ is the indicated propulsive energy (J), which equals the energy produced by the combustion of fuel in the engine [16]. $F_{i}$ is the indicated driving force $(\mathrm{N}) . F_{t}$ is the resistance $(\mathrm{N})$ of the transmission system, which is numerically equal to the force to maintain the normal operation of the transmission system. $n_{t f}$ is the transmission efficiency, which is reflected in the mechanical loss of each part of the transmission system (transmission, transmission shaft, and differential and drive shaft). When predicting vehicle performance, the transmission efficiency is usually considered to be $85 \%$ [16-18]. $S$ is the travel distance $(m) . F_{a}$ is the air resistance $(\mathrm{N}) . A$ is the frontal area of the vehicle $\left(\mathrm{m}^{2}\right)$, which is the area of the car from the front to the rear [18]. The air resistance coefficient $C_{D}$ is related to the vehicle's contour. For a common passenger car, $C_{D}=0.3-0.5$. For a common truck, $C_{D}=0.4-1.0$ [18]. The air resistance coefficients of various shapes of vehicles were obtained from the literature $[18,20] . \rho$ is the air density, which is generally taken as $1.2258 \mathrm{~N} \cdot \mathrm{s}^{2} / \mathrm{m}^{4}$. $V$ is the relative vehicle speed taking into account the effect of wind $(\mathrm{m} / \mathrm{s})$. The rolling coefficient $C_{r}$ is related to the pavement type and pavement condition, i.e., smoothness of the road surface. Energy is also required on a soft and deformable road surface; this energy consumption also belongs to rolling resistance. The factors that determine the pavement condition are road grade, road structure, hardness, and dryness. Values for pavement conditions were obtained here from the literature $[21,22]$ as determined empirically. $v$ is the vehicle velocity $(\mathrm{km} / \mathrm{h})$. The rolling resistance constants $C_{2}$ and $C_{3}$ are related to tire type, and the parameter values are determined empirically. For the radial tires commonly used in passenger cars, $C_{1}=0.044$ and $C_{2}=5.3[19]$. For the radial tires generally used in trucks, $C_{1}=0.0328$ and $C_{2}=4.575[16,23]$.

There are three driving behaviors on downhill sections (driving in the gear position and releasing the accelerator pedal, driving while pressing the accelerator, and braking, respectively) [9]. The formulas for estimating the total propulsive energy of a vehicle operating at cruising speed on a downhill section can be expressed as shown in equations (7)-(9). When the vehicle is driven downhill in the gear position with a released accelerator pedal, the transmission system generates antitraction to the vehicle as the direction of torque flow is reversed. Under different longitudinal slope conditions, in order to keep the vehicle moving downhill at a constant speed, the gravitational potential energy and the driving resistance must be balanced. When the vehicle drives in the gear position and the accelerator pedal is released, the downhill segment with no propulsive force is dependent on the steepness of the downgrade section $[4,9,10]$ :

$$
\begin{aligned}
E_{g} & =W_{r}+W_{a}+W_{t}^{\prime}, \\
W+E_{g} & =W_{r}+W_{a}, \\
E_{g} & =W_{r}+W_{a}+W_{t}+W_{h},
\end{aligned}
$$

where $W_{h}$ is the energy loss (J) caused by vehicle braking and $W_{t}^{\prime}$ is the energy (J) lost by the antitraction force, $F_{t}^{\prime}$.

$$
W_{t}=F_{t}^{\prime} S \text {. }
$$

The force and energy conversion formula of vehicles on these road sections were adapted from Xu et al. $[9,10]$, Gillespie [16], Crolla and Mashadi [17], and Wong [18] and have been widely verified previously.

\subsection{Conversion of Energy, Fuel Consumption, and $\mathrm{CO}_{2}$} Emissions. Propulsive energy is closely related to fuel consumption and carbon emissions [9-14]. The thermal energy provided by the engine in burning fuel is converted into mechanical energy that drives the vehicle. The currently implemented vehicle standards in China affect vehicle performance and fuel characteristics, thereby affecting vehicle carbon emissions. In recent years, China's motor vehicles have been required to meet the national fifth-phase motor vehicle pollutant emission standards [24]. For the naturally aspirated gasoline engines that are typically used in economical passenger cars, the fuel utilization rate is $27 \%$. For the ordinary compression-ignition diesel engines commonly used in medium-duty trucks, the fuel utilization rate is $40 \%$. For the Xichai compression-ignition diesel engines generally installed in heavy-duty trucks, the fuel utilization rate is $45 \%[8,25]$. Diesel vehicles are required to use urea additive as an exhaust gas purifying agent under China's National Motor Vehicle Emissions Standard. The concentration of urea additive currently supplied for diesel trucks in China is 35\% [26]. The characteristics of fuels supplied to vehicles also must meet the national fifth-phase standards of fuel for motor vehicles [27, 28]. According to China's vehicle fuel energy statistics [29] and the national communications on climate change in China [30,31], there are relevant quality indexes on vehicle fuels available for reference. For gasoline and diesel, the average low calorific values are $44.800(\mathrm{TJ} / \mathrm{Gg})$ and $43.330(\mathrm{TJ} / \mathrm{Gg})$, respectively. The potential carbon emission factors are $18.9(\mathrm{t} / \mathrm{TJ})$ and $20.2(\mathrm{t} / \mathrm{TJ})$, respectively. The densities of gasoline types $92 \#$, $95 \#$, and $98 \#$ are $0.725 \mathrm{~kg} / \mathrm{L}, 0.737 \mathrm{~kg} / \mathrm{L}$, and $0.753 \mathrm{~kg} / \mathrm{L}$, respectively. The densities of diesel types $0 \#$ and $-10 \#$ are $0.835 \mathrm{~kg} / \mathrm{L}$ and $0.84 \mathrm{~kg} / \mathrm{L}$, respectively [29].

The IPCC conversion model recommended in the IPCC Climate Change Assessment Report [12, 24] is authoritative in converting vehicle fuel consumption to carbon emissions $[13,14]$. By using the IPCC accounting method and considering the characteristics of Chinese vehicles and fuels, $\mathrm{Xu}$ et al. $[9,10]$ obtained the conversion relationship between 
energy, fuel consumption, and carbon emissions specific to China. The carbon emissions of different fuel densities when the vehicle is traveling with the indicated driving energy can be determined by the following equations:

$$
\begin{aligned}
\mathrm{CO}_{2}(92 \#)= & 2.959 W_{i} \times 10^{-7}+2.206 q_{0} t \\
\mathrm{CO}_{2}(95 \#)= & 2.959 W_{i} \times 10^{-7}+2.242 q_{0} t \\
\mathrm{CO}_{2}(98 \#)= & 2.959 W_{i} \times 10^{-7}+2.291 q_{0} t \\
& \times 10^{-8}+0.373 M q_{0} t \\
\mathrm{CO}_{2}(0 \#)= & 2.135 W_{i} \times 10^{-7}+2.626 q_{0} t+3.030 M W_{i} \\
& \times 10^{-8}+0.368 M q_{0} t
\end{aligned}
$$

where $\mathrm{CO}_{2}$ is the carbon emission $(\mathrm{kg}), q_{0}$ is the fuel consumption at idle state $(\mathrm{L} / \mathrm{h}), t$ is the travel time $(\mathrm{h})$, and $M$ is the consumption of urea additive $(\mathrm{kg})$.

\subsection{Carbon Emission Model}

2.3.1. Longitudinal Vertical Curves. At the turning point of the two longitudinal slope sections of the vertical profile, a quadratic parabola is usually adopted as a vertical curve to connect the two longitudinal slope sections [32] (Figure 2). The general expression of the vertical curve shown in Figure 2 is given in the following equation:

$$
y=\frac{x^{2}}{2 k}+i x,
$$

where $x$ is the horizontal distance $(m)$, that is, the distance from any point of the vertical curve to the starting point of the vertical curve, and $i$ is the gradient of any point of the vertical curve, $i=x / R+i_{1}$. At the starting point of the vertical curve, $x=0$, and $i=i_{1}$. At the end of the vertical curve, $x=L$, and $i=i_{1}+L / R+i_{2}$ [32].

The design elements of the vertical curve mainly include radius $R$, length $L$, and gradient difference $w, w=i_{2}-i_{1}$ [32]. The relationship between them is shown in the following equation:

$$
R=\frac{L}{w}
$$

A positive $w$ indicates a concave vertical curve; conversely, a negative $w$ refers to a convex vertical curve. The form of the vertical curve is closely related to the terminal gradients of the vertical curve. The slope of the vertical curve section changes continuously. The vertical curve section is a combination of several parts with different longitudinal slopes at each point of the vertical curve $[1,4]$. The average gradient of the vertical curve section is the average value of

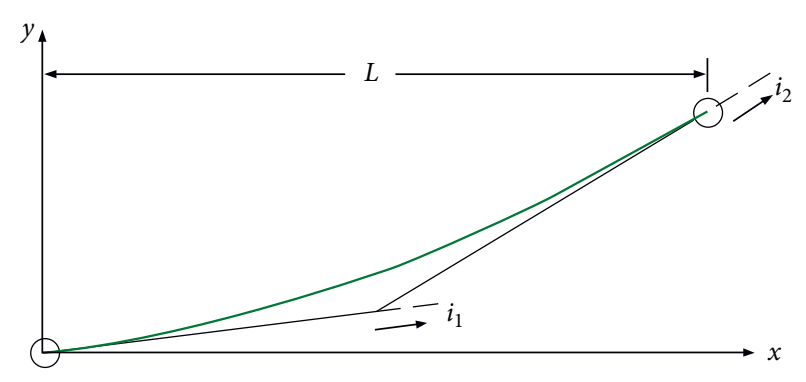

FIGURE 2: Schematic diagram of vertical curve elements.

the terminal gradients of the vertical curve, as shown in the following equation:

$$
\bar{i}=\frac{1}{L} \int_{0}^{L}[i(x) \cdot L(x)] \mathrm{d} x=\frac{i_{1}+i_{2}}{2} .
$$

The carbon emission rate, $C$, of the vehicle on the vertical curve section can be calculated by the following equation $[1,4]$ :

$$
C=\frac{1}{L} \int_{0}^{L} C(x) \mathrm{d} x .
$$

The vertical curve's form is greatly affected by its terminal gradients. When the two terminal longitudinal slopes both are uphill or downhill, and with a tendency of uphill or downhill movement, the curve is referred to as a longitudinal vertical curve. When the terminal longitudinal slopes are uphill and downhill, respectively, the vertical curve is in a crest or sag form. The vertical curve is symmetrical or asymmetrical depending on whether the two terminal absolute gradients are equal or unequal [32].

The longitudinal vertical curve can be divided into uphill and downhill trends from the perspective of force analysis; this division creates an "uphill vertical curve" and "downhill vertical curve," respectively. The driving energy on the uphill vertical curve can be obtained according to equation (20). The driving energy necessary to traverse the uphill vertical curve is equal to the driving energy moving uphill with an average gradient and equal mileage, as shown in equation (21). Integrating equations (18) and (21) allow the driving energy on the uphill vertical curve section to be determined as equation (22):

$$
\begin{aligned}
& W_{\text {up }}=\int_{0}^{L}\left[F_{a}+F_{r}+F_{g}(x)\right] \mathrm{d} x, \\
& W_{\text {up }}=L\left(F_{a}+F_{r}+m g \bar{i}\right), \\
& W_{\text {up }}=L\left[F_{a}+F_{r}+m g\left(\frac{i_{1}+i_{2}}{2}\right)\right],
\end{aligned}
$$

where $W_{\text {up }}$ is the vehicle's propulsive energy (J) on uphill vertical curve section.

The fuel consumption of the engine in the idle state is the source of energy required to maintain the normal operation of the engine and to provide the normal operation of various vehicle parts (e.g., the brake, steering system booster pumps, and air-conditioning compressor). 
The idling fuel consumption determines the idle carbon emissions $C_{0}$. The carbon emission rate on the uphill vertical curve section, $C_{\text {up }}$, is the sum of the carbon emission rate generated by driving energy and the idle carbon emission rate, shown as follows [11]:

$$
C_{\text {up }}=C_{L}+C_{0},
$$

where $C_{L}$ is the carbon emission rate generated by driving energy throughout the travel distance $L$.

In scenario $D 1$, the terminal gradients of the downhill vertical curve are not greater than the balance gradient. The accelerator must be pressed to provide sufficient driving energy as per the relationship shown in equation (24). For the downhill vertical curve in this scenario, the driving force energy is equal to the energy on the downhill with the average gradient and equal mileage, as shown in equation (25):

$$
\begin{aligned}
& W_{\text {Down }}=\int_{0}^{L}\left[F_{a}+F_{r}-F_{g}(x)\right] \mathrm{d} x, \\
& W_{\text {Down }}=L\left[F_{a}+F_{r}-m g\left(\frac{i_{1}+i_{2}}{2}\right)\right],
\end{aligned}
$$

where $W_{\text {down }}$ is the propulsive energy (J) of the vehicle on the downhill vertical curve section.

The carbon emission rate under scenario $D 1, C_{D 1}$, is determined by the energy of propulsion and idling as the vehicle traverses the entire highway section, as shown in equation (26). According to equation (25), the carbon emission rate in this scenario is equal to the carbon emission rate on a downhill section with the average gradient:

$$
C_{D 1}=C_{L}+C_{0} .
$$

In scenario $D 2$, one of the terminal gradients of the downhill vertical curve is greater than the balance gradient. The driving energy and carbon emission rate in D2 were divided into two cases according to the traction force situation, as shown in Figure 3.

The carbon emission rate in scenario $D 2, C_{D 2}$, can be calculated by as follows:

$$
C_{D 2} L=C_{0} L+C_{L 1} L_{1},
$$

where $C_{L 1}$ is the carbon emission rate generated by driving energy throughout the travel distance $L_{1}$.

The values for $L, L_{1}$, and $L_{0}$ were determined as follows:

$$
\begin{aligned}
L & =\left(i_{2}-i_{1}\right) R, \\
L_{1} & =\left(i_{B}-i_{1}\right) R, \\
L_{0} & =L-L_{1} .
\end{aligned}
$$

According to equations (27)-(30), the carbon emissions of the vehicle in scenario $D 2$ can be expressed as equation (31). The carbon emission rate is related to the balance gradient and the terminal gradients of the vertical curve:

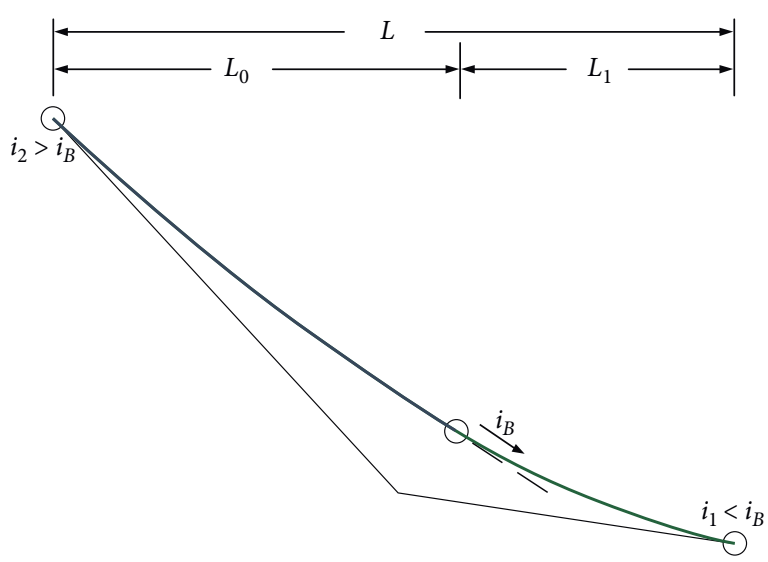

FIGURE 3: Schematic diagram of downhill vertical curve in scenario D2.

$$
C_{D 2}=C_{0}+C_{L 1} \frac{\left(i_{B}-i_{1}\right)}{\left(i_{2}-i_{1}\right)}
$$

In scenario D3, the terminal gradients of the vertical curve are greater than the balance gradient and no propulsive energy is required. The carbon emission rate in scenario $D 3, C_{D 3}$, is the idling carbon emission rate as shown in the following equation:

$$
C_{D 3}=C_{0} .
$$

Equations (23), (26), (31), and (32) indicate that the sequencing of the carbon emission rate on the longitudinal vertical curve is shown as follows:

$$
C_{\text {up }}>C_{D 1}>C_{D 2}>C_{D 3}
$$

2.3.2. Symmetrical and Asymmetric Vertical Curve. The typical fully sag and crest vertical curve forms are classified into symmetrical and asymmetrical depending on whether the absolute terminal vertical curve gradients are equal or not.

(1). Symmetrical Vertical Curve. According to vehicle's force conditions, the symmetrical vertical curve can be divided into uphill and downhill vertical curve sections. The absolute gradient and length of the two symmetrical sections of the vertical curve are equal. In scenario S1, the terminal gradients of the symmetrical vertical curve are less than the balance gradient; the vehicle's accelerator must be pressed down to maintain a cruise speed during travel. As shown in equations (20) and (24), the driving energy is equal to that on the flat section with equal mileage:

$$
W_{S}=L\left(F_{a}+F_{r}\right) \text {, }
$$

where $W_{s}$ is the propulsive energy ( $\left.\mathrm{J}\right)$ on the symmetrical vertical curve section.

As shown in equation (34), the carbon emission rate of vehicle in scenario $\mathrm{S} 1$ is equal to that on the flat section: 


$$
C_{S 1}=C_{F}
$$

where $C_{S 1}$ and $C_{F}$ represent the carbon emission rates of the vehicle on the symmetrical vertical curve section in scenario $S 1$ and the flat section, respectively.

In scenario $S 2$, the terminal gradients of the symmetrical vertical curve are equal to the balance gradient. No propulsive energy is needed on the downhill vertical curve section. Driving energy in this case can be divided into two categories according to the traction force situation, as shown in Figure 4. The work done by the indicated tractive force on the symmetrical vertical curve follows equation (36). On integrating, equations (2), (7), and (36) allow the energy supplied from the engine to be determined by equation (37). The difference between the energy consumed by the transmission system and the energy loss caused by reverse tractive force is usually ignored in the derivation of vehicle longitudinal power [17]. The driving energy of the vehicle in this scenario can be determined by equation (38):

$$
\begin{aligned}
W_{s}=W_{L_{2}} & =\int_{0}^{L_{2}}\left[F_{a}+F_{r}+F_{g}(x)\right] \mathrm{d} x, \\
W_{s}+\int_{0}^{L_{2}} F_{t}(x) \mathrm{d} x & =L\left(F_{a}+F_{r}\right)+\int_{0}^{L_{1}} F_{t}^{\prime}(x) \mathrm{d} x, \\
W_{s} & \approx L\left(F_{a}+F_{r}\right),
\end{aligned}
$$

where $W_{L 2}$ is the propulsive energy $(\mathrm{J})$ on the $L_{2}$ sections shown in Figure 4.

The carbon emission rate of the vehicle on the symmetrical vertical curve section in scenario $S 2, C_{S 2}$, is approximately equal to that on the flat section, as follows:

$$
C_{S 1} \approx C_{F} \text {. }
$$

In scenario S3, the terminal gradients of the symmetrical vertical curve are greater than the balance gradient. The vehicle needs to brake to maintain a cruise speed during downhill travel in this case. The vehicle driving energy can be divided into three parts, as shown in equations (40)-(42). Integrating equations (9) and (40)-(42) allows the energy loss caused by braking on vertical curve's downhill trend section with the gradient greater than the balance gradient to be determined by equation (43). The energy loss caused by braking is equal to the difference between the driving energy on the vertical curve section and the equal mile flat section:

$$
\begin{aligned}
W_{s} & =W_{1}+W_{0}+W_{2} \\
W_{1} & =0 \\
W_{2} & =\int_{0}^{L_{2}}\left[F_{a}+F_{r}+F_{g}(x)\right] \mathrm{d} x \\
W_{s}+\int_{0}^{L_{2}} F_{t}(x) \mathrm{d} x & =L\left(F_{a}+F_{r}\right)+\int_{0}^{L_{1}}\left[F_{h}(x)+F_{t}^{\prime}(x)\right] \mathrm{d} x
\end{aligned}
$$

$$
W_{s} \approx L\left(F_{a}+F_{r}\right)+\int_{0}^{L_{1}} F_{h}(x) \mathrm{d} x,
$$

where $W_{0}, W_{1}$, and $W_{2}$ are the vehicle propulsion energy (J) on the $L_{0}, L_{1}$, and $L_{2}$ sections shown in Figure 5, respectively; $F_{h}$ is the braking force $(\mathrm{N})$.

In scenario $S 3$, the carbon emission rate can be determined by the following equation:

$$
C_{S 3} L=C_{F} L_{0}+C_{L 2} L_{2}
$$

where $C_{L 2}>C_{F}$. $C_{L 2}$ is the carbon emission rate generated by driving energy throughout the travel distance $L_{2}$.

The values for $L, L_{0}, L_{1}$, and $L_{2}$ were determined with the following equations:

$$
\begin{aligned}
L & =2 i R, \\
L_{0} & =2 i_{B} R, \\
L_{1} & =L_{2}=\left(i-i_{B}\right) R .
\end{aligned}
$$

The vehicle's carbon emission rate can be determined by equation (49) according to equations (45)-(48); said rate, in this scenario, is related to the terminal gradients and balance gradient. The carbon emission rule of the crest vertical curve is the same as that of the sag vertical curve:

$$
C_{S 3}=C_{F}+\left(C_{L 2}-C_{F}\right) \frac{\left(i-i_{B}\right)}{(2 i)}
$$

It can be seen in equations (35), (39), and (49) that the sequencing of the carbon emission rate on the symmetrical vertical curve is shown in the following equation:

$$
C_{S 3}>C_{S 2}>C_{S 1} \text {. }
$$

(2). Asymmetrical Vertical Curve. The asymmetric vertical curve can be divided into two sections according to its physical composition: a symmetrical vertical curve and a vertical curve with an uphill or downhill trend (Figure 6). The propulsive energy can be divided into two sections, expressed as follows:

$$
W_{\mathrm{as}}=L_{1}\left(F_{a}+F_{r}\right)+L_{2}\left[F_{a}+F_{r} \pm m g\left(\frac{i_{2}-i_{1}}{2}\right)\right] \text {, }
$$

where $W_{\text {as }}$ is the propulsive energy (J) on the asymmetrical vertical curve section. When $x=L_{1}, i=i_{1}+\left(L_{1} / R\right)=-i_{1}$; $L_{2}=L-L_{1}$.

The quantification of vehicle's carbon emissions on asymmetric vertical curve sections can also be divided into two parts: the uphill trend and the downhill trend sections from the slope of zero. The goal of this study was to determine the carbon emission rules of different forms of vertical curve sections, so the determined quantitative method was adopted here.

The above analysis indicates that the carbon emission rate of the vehicle on the vertical curve is determined by the balance gradient and the terminal gradients of the vertical 


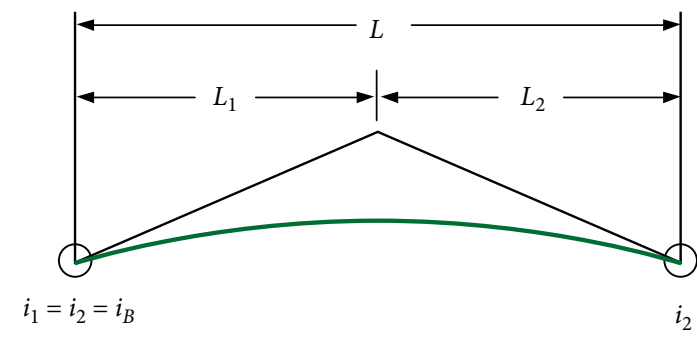

(a)

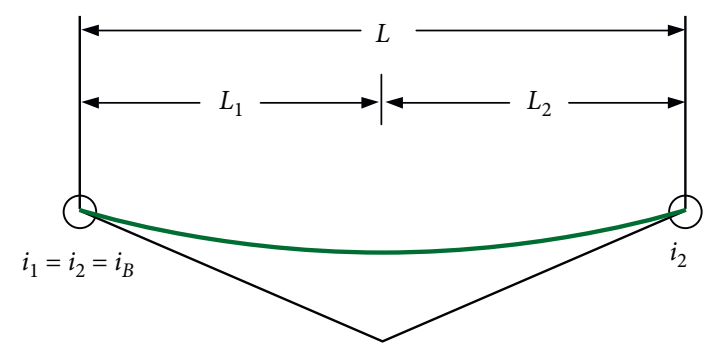

(b)

Figure 4: Symmetrical vertical curves in scenario S2: (a) crest; (b) sag.

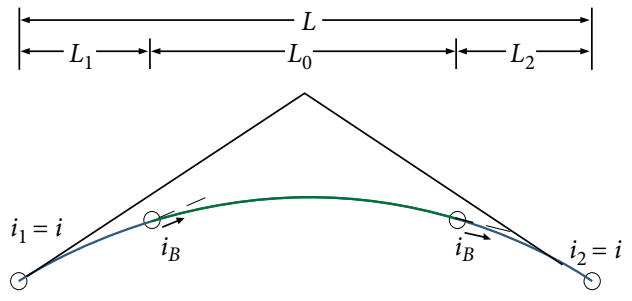

(a)

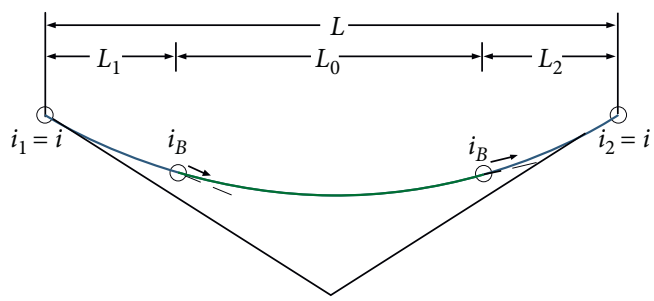

(b)

Figure 5: Symmetrical vertical curves in scenario S3: (a) crest; (b) sag.

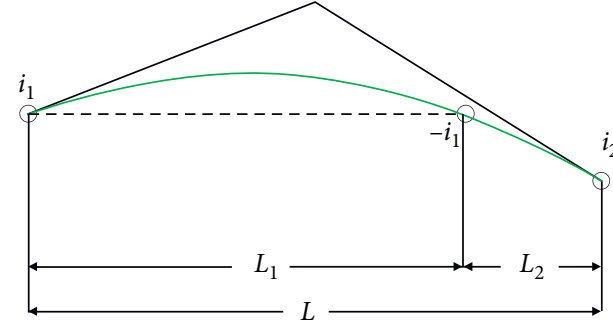

(a)

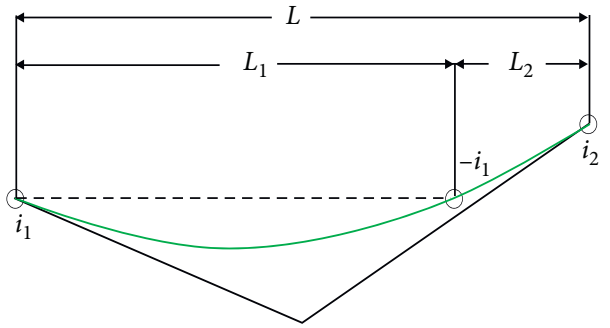

(b)

Figure 6: Asymmetric vertical curve: (a) crest; (b) sag.

curve and is irrelevant to the radius or crest/sag form of the curve. Before predicting the vehicle's carbon emissions, the type of the vertical curve should be figured out by its balance gradient and terminal gradients.

During the low-carbon design of the vertical curve, controlling the terminal gradient of the vertical curve to be less than the balance gradient can make the carbon emission rate of the two-way traffic on the vertical curve equal to the carbon emission rate of the flat section.

On the vertical profile of the actual road, the vertical curve and longitudinal slope sections are sequential. The cumulative carbon emissions on the vertical profile section can be determined by the following equations:

$$
\begin{aligned}
& \mathrm{CO}_{2 \text { (profile) }}=\sum_{j=1}^{n} \mathrm{CO}_{2}(j), \\
& \mathrm{CO}_{2 \text { (curve) }}=C_{v}\left(i_{2}-i_{1}\right) R, \\
& \mathrm{CO}_{2 \text { (slope) }}=C_{i} L_{i},
\end{aligned}
$$

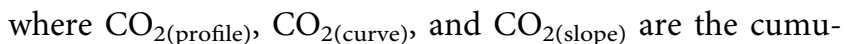
lative carbon emissions $(\mathrm{kg})$ of vehicle on the vertical profile, vertical curve, and longitudinal slope sections, respectively. $C_{v}$ and $C_{i}$ are the carbon emission rates $(\mathrm{kg} / \mathrm{m})$ of vehicle on the vertical curve and longitudinal slope sections. $L_{i}$ is the distance of the longitudinal slope section $(m)$.

2.4. Field Experiments. Field experiments can directly reflect the actual operation conditions and carbon emissions of a given vehicle, so field research was applied in this study. Typical flat, longitudinal slope, and vertical curve road sections were selected to measure vehicle velocity and fuel consumption data of vehicles traversing them. The IPCC conversion model was used to convert fuel consumption to carbon emissions.

2.4.1. Instruments and Vehicles. An Ecan analyzer was adopted to derive the velocity, travel time, and fuel consumption data of passenger cars in the field test. The fuel 
consumption, speed, and travel time of trucks were measured with a diesel fuel consumption instrument JDSZ-EP1-1D. An anemometer monitoring instrument AS8336 was used to measure wind speed. These devices have second-tosecond sampling frequencies. The accuracy values of velocity, fuel consumption, and wind speed data are $0.1 \mathrm{~km} / \mathrm{h}$, $0.1 \mathrm{~mL}$, and $0.001 \mathrm{~m} / \mathrm{s}$, respectively; the measurement errors are within $\pm 3 \%, \pm 0.5 \%$, and $\pm 3 \%$, respectively. The wind speed was required to be small and stable during the test. Any breeze with speed below $6.0 \mathrm{~m} / \mathrm{s}$ has almost no effect on the movement of ground objects. The wind speed was required to be below $6.0 \mathrm{~m} / \mathrm{s}$ and allowed to fluctuate within the range of $2.0 \mathrm{~m} / \mathrm{s}$ during the test $[16,19]$. The average measured wind speed was taken as the wind speed value.

A traffic survey was conducted before the experiment. An AxleLightRLU11 vehicle classification statistical instrument was placed on the test roads prior to select the passenger car and truck with a large traffic volume. This instrument automatically collects and records vehicle performance data consisting of vehicle count, timely speed, vehicle type, and headway time with a high accuracy. It is small enough to be easily placed on the outermost edge of the hard shoulder and without affecting the behavior of passing motorists. Based on the traffic volume data on the test road and the development prospects of vehicles, two types of common passenger cars and three types of common trucks were selected as the dominant vehicle types. In order to ensure the reliability of the test data, 10 of each type of test vehicle were used in the test. The characteristics of the test vehicles are the same as the dominant vehicle types (Table 3).

2.4.2. Participants. Driver performance varies depending on personal driving preferences and experience, so drivers were screened before the field test to ensure they were sufficiently experienced and familiar with the road. Each driver was given 10 days of training and testing to prevent any incorrect driving operations from affecting the test results. The drivers were required to maintain a normal cruising speed and to maintain a safe distance from the vehicle in front of them. The driving behavior of the test vehicle was not impacted by the other vehicles on the road. Fifty healthy male drivers between 15 and 20 years of driving experience passed the test. Each test vehicle type was assigned 10 drivers.

2.4.3. Road Conditions. The field test was conducted on highways of different road grades. On the Xibao Expressway, the Hanzhong-Mianxian first-grade highway, and the S306 provincial highway, the flat straight sections were selected to measure the fuel consumption of vehicles travel at a uniform speed. On the Hanzhong-Mianxian first-grade highway (road I), Xunyi-Qiupotou second-grade highway (road II), and Xianyang-Xunyi expressway (road III), longitudinal sections and vertical curve sections were selected to measure the speed and fuel consumption data on uphill, downhill, and various vertical curve sections.

The speed was controlled within the speed limit requirements of the actual road throughout the test. The Xibao Expressway and Xianyang to Xunyi Expressway are composed of asphalt pavements in excellent condition. The rolling resistance coefficient is 1.25 , the wind speed is 1.0 $\mathrm{m} / \mathrm{s}$, and the speed limits of passenger cars and trucks are $60-120 \mathrm{~km} / \mathrm{h}$ and $60-100 \mathrm{~km} / \mathrm{h}$, respectively. The first-grade highway from Hanzhong to Mianxian is an asphalt pavement in fair condition. The rolling resistance coefficient is 1.5 , the wind speed is $3.0 \mathrm{~m} / \mathrm{s}$, and the speed limit for passenger cars and trucks is $60-100 \mathrm{~km} / \mathrm{h}$ and $60-80 \mathrm{~km} / \mathrm{h}$, respectively. The S306 Provincial Highway and Xunyi to Qiupotou second-grade road are composed of asphalt pavement in poor condition. The rolling resistance coefficient is 2.5 , the wind speed is $6.0 \mathrm{~m} / \mathrm{s}$, and the speed limit ranges of passenger cars and trucks are $40-80 \mathrm{~km} / \mathrm{h}$ and $40-60 \mathrm{~km} / \mathrm{h}$, respectively.

2.4.4. Other Influencing Factors. The experimental conditions were strictly controlled to eliminate the impact of any other factors on the vehicle carbon emission data gathered in this study. Experimental segments were required to be basic road sections; test locations were at least $1000 \mathrm{~m}$ away from any ramps, toll stations, bridges, and tunnels. The traffic flow in the test road was required to be in a free flow pattern with no other vehicles affecting the drivers' normal operation of their vehicles. Traffic flow patterns and vehicle operating conditions were monitored in real time with the AxleLightRLU11 vehicle classification instrument. Consistent road pavement type and conditions were maintained throughout the test. The route's horizontal alignment was a straight line or a curve with a radius greater than $2000 \mathrm{~m}$ $[13,32]$. The weather was required to be mild with no fog. The driver used the cruise control function to maintain a cruise speed and began the test once the velocity stabilized. Every group of data was collected and averaged at least 30 times on each test road section. The experiment was carried out from June 10 to August 30 between 8 a.m. and 6 p.m. These considerations altogether ensured the objectivity and reliability of the collected test data.

2.4.5. Descriptive Statistics Test. According to probability theory, the tested carbon emission data should conform to the normal distribution [33]. The tested carbon emission data were subjected to descriptive statistical tests to determine whether this was the case in this study. Taking car I driving at a cruising speed of $100 \mathrm{~km} / \mathrm{h}$ on the vertical curve as an example, the descriptive statistics test results are shown in Figure 7 and Table 4 . The vertical curve section was designed with a front gradient of $1.2 \%$, a back gradient of $0.6 \%$, and a radius of $54 \mathrm{~km}$.

Figure 7(a) shows that the distribution form of the tested carbon emission data in this case basically conforms to the normal distribution. Figure 7(b) shows that the tested data fluctuate in a small range on the standard line and has equal variance. As listed in Table 4, the mean value is greater than the standard deviation, the absolute value of kurtosis is less than 10 , and the absolute value of skewness is less than 3 . The Shapiro-Wilk test results show that Sig. $=0.681>0.5$ [33]. The descriptive statistical test results thus indicate that the 
TABLE 3: Test vehicles information.

\begin{tabular}{lcccc}
\hline Variable & & \multicolumn{2}{c}{ Specification } \\
Vehicle type & Passenger car & SUV & Medium truck & Heavy-duty truck \\
\hline Label & Car I & Car II & Truck I & Truck II \\
Mass $(\mathrm{t})$ & 1.65 & 1.88 & 15 & 28 \\
Frontal area $\left(\mathrm{m}^{2}\right)$ & 1.80 & 2.0 & 5.64 & 5.64 \\
Air resistance coefficient & 0.35 & 0.50 & 0.50 & 0.46 \\
Engine type & Naturally aspirated & Compression-ignition & 6.08 \\
Fuel type & \multicolumn{2}{c}{ 92\# gasoline } & & $-10 \#$ diesel compression-ignition \\
\hline
\end{tabular}

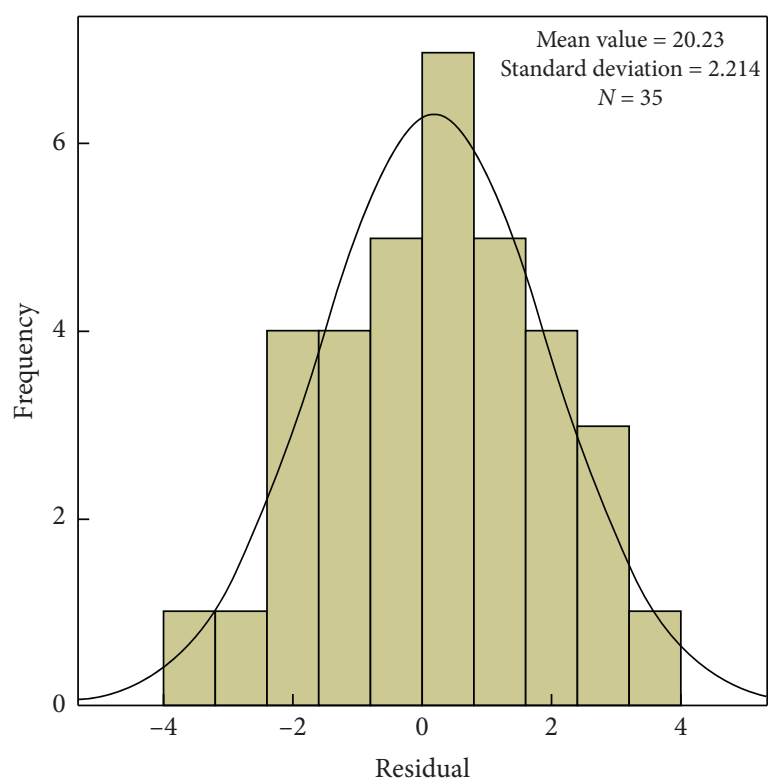

(a)

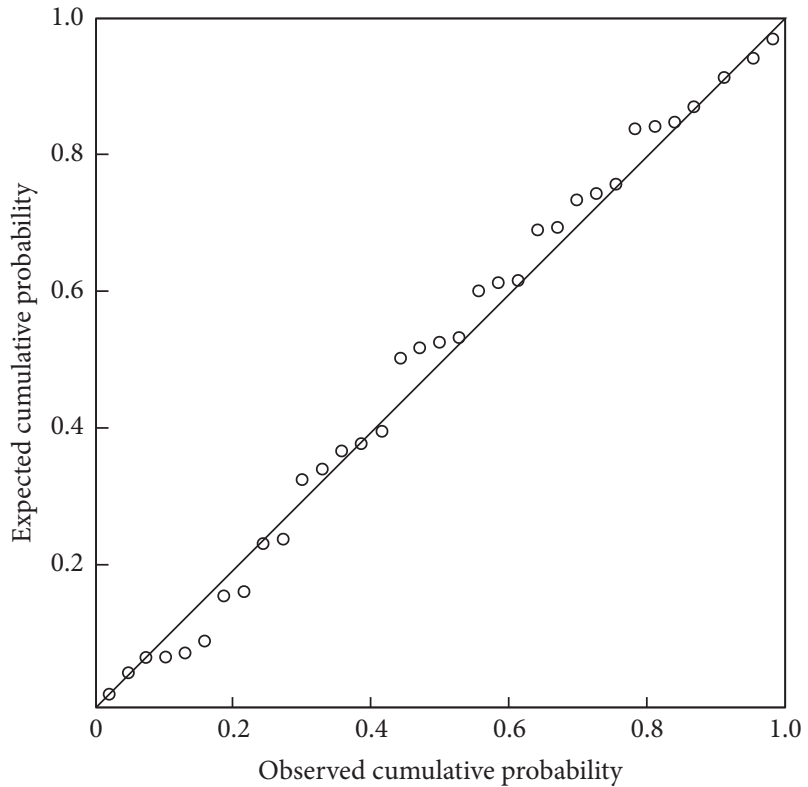

(b)

Figure 7: Normal distribution test of the data: (a) histogram; (b) P-P plot.

TABle 4: Parameter values of the descriptive statistics test.

\begin{tabular}{lccccccccc}
\hline & \multicolumn{3}{c}{ Descriptive analysis } & \multicolumn{3}{c}{ Shapiro-Wilk } \\
Minimum & Maximum & Mean & Variance & Standard deviation & Skewness & Kurtosis & Statistics & df & Sig. \\
\hline 15.71 & 24.32 & 20.23 & 4.904 & 2.214 & -0.186 & -0.762 & 0.978 & 35 & 0.681 \\
\hline
\end{tabular}

measured carbon emission data follow the normal distribution.

\section{Results and Discussion}

3.1. Validity of Proposed Model. The field test data were used to evaluate the accuracy of the carbon emission model established here. The influence of vertical curve design indexes on vehicle carbon emissions was determined by comparing the carbon emissions of vehicles on flat sections, longitudinal slope sections, and different forms of vertical curve sections. Each group of experimental results for comparisons was analyzed under scenarios where wind speed, road conditions, and other factors were basically the same.

A clear balance gradient allowed for easy verification of the carbon emission rules of vehicles on vertical curves. The rule of the balance gradient from shallow to steep grades versus velocities was confirmed recently by Xu et al. $[9,10]$ and Chang and Morlok [6]. Table 5 shows the balance gradients of test vehicles at different velocities proposed by $\mathrm{Xu}$ et al. $[9,10]$, which was considered here the speed limit regulation on different road grades.

During the field tests, test trucks I, II, and III consumed 3,5 , and 7 liters of urea additives, respectively, for every 100 liters of diesel consumed.

Table 6 shows the vehicle carbon emissions of 22 test cases on the longitudinal vertical curve sections. The maximum relative error (Diff.) of predicted and tested carbon emissions of the test vehicles is $9.94 \%$, which suggests that the proposed model is accurate. Test sections with different design speed sections were selected to enrich the sample size of vertical curve sections with different forms. The test data with a lower speed have a larger relative error 
TABLE 5: Balance gradients of test vehicles under different velocity conditions.

\begin{tabular}{lcccccc}
\hline \multirow{2}{*}{ Road } & \multirow{6}{c}{ Vehicles balance gradient (\%) } \\
& 40 & 2.80 & 3.00 & 2.00 & 1.90 & 1.90 \\
& 50 & 3.30 & 3.50 & 2.30 & 2.00 & 2.00 \\
\multirow{4}{*}{ Road I } & 60 & 3.60 & 4.00 & 2.60 & 2.30 & 2.30 \\
& 70 & 4.20 & 4.50 & - & - & - \\
& 80 & 4.60 & 5.00 & - & - & - \\
& 60 & 2.40 & 2.00 & 1.70 & 1.30 & 1.30 \\
Road II & 70 & 2.80 & 2.50 & 1.90 & 1.50 & 1.50 \\
& 80 & 3.20 & 3.00 & 2.20 & 1.70 & 1.70 \\
& 90 & 3.50 & 3.50 & - & - & - \\
& 100 & 4.00 & 4.00 & - & - & - \\
& 60 & 2.00 & 4.50 & 1.30 & 1.20 & 1.20 \\
& 70 & 2.50 & 5.00 & 1.50 & 1.30 & 1.30 \\
Road III & 90 & 2.80 & 3.00 & 1.80 & 1.50 & 1.50 \\
& 90 & 3.00 & 3.50 & 2.00 & 1.60 & 1.60 \\
& 100 & 3.50 & 4.00 & 2.20 & 1.80 & 1.80 \\
& 110 & 4.00 & 4.50 & - & - & - \\
\hline
\end{tabular}

than the test data with high speed, as the driver was required to adjust to a cruising speed on the shorter flat road section in front of the test section.

Table 6 shows that, for a downhill vertical curve with terminal gradients not greater than the balance gradient and for the uphill vertical curve as well, the carbon emission rates are basically equal to those on the longitudinal slope with the average gradient. The test passenger cars and trucks in this scenario are shown in nos. 1-19 and 1-13, respectively. The maximum relative error of the measured carbon emissions of test vehicles following this rule is $9.85 \%$.

When the test passenger cars and trucks traversed the downhill vertical curve with one of the terminal gradients greater than the balance gradient (nos. 20-22 and 14-22), the carbon emission rate appears to be determined by the balance gradient and terminal gradients. There is a large difference between the carbon emission rates on the vertical curve and those on the longitudinal slope with an average gradient.

When the terminal gradients of the downhill vertical curve are greater than the balance gradient, the carbon emission rate is equal to that in the idle state.

The carbon emission measurements of 12 test cases on the symmetrical vertical curve sections are shown in Table 7. The maximum relative error of test vehicles between the predicted and measured carbon emissions is $9.51 \%$.

The measured carbon emissions of car I, car II, truck I, truck II, and truck III maintaining cruise speeds of $100 \mathrm{~km} / \mathrm{h}$ and $60 \mathrm{~km} / \mathrm{h}$ on the flat section are $15.68 \mathrm{~kg} / 100 \mathrm{~km}$, $16.70 \mathrm{~kg} / 100 \mathrm{~km}, 22.17 \mathrm{~kg} / 100 \mathrm{~km}, 20.77 \mathrm{~kg} / 100 \mathrm{~km}$, and $60.30 \mathrm{~kg} / 100 \mathrm{~km}$ and $79.55 \mathrm{~kg} / 100 \mathrm{~km}, 79.06 \mathrm{~kg} / 100 \mathrm{~km}$, $103.68 \mathrm{~kg} / 100 \mathrm{~km}, 108.74 \mathrm{~kg} / 100 \mathrm{~km}$, and $154.83 \mathrm{~kg} / 100 \mathrm{~km}$, respectively. When the gradients at both ends of the symmetrical vertical curve are less than the balance gradient, the carbon emission rate of any vehicle is almost equal to that on the flat road; the maximum relative errors for passenger cars and trucks are $8.88 \%$ and $8.22 \%$, respectively. Compared to the flat road section, the difference in carbon emissions between the uphill and the downhill sections of the vertical curve appear to offset each other. Moreover, there is no energy loss due to braking as the vehicle travels downhill and no additional propulsion energy during uphill driving.

When the terminal gradients of the symmetrical vertical curve are greater than the balance gradient, the carbon emission rate is greater than that on flat road. More driving energy is necessary on the upward curve segment where the gradient is greater than the balance gradient to offset the braking energy loss during downhill driving. Carbon emissions increase as the terminal gradients of the symmetrical vertical curve increase. In the design process, the gradient of the longitudinal slope should be kept below the balance gradient to minimize vehicle carbon emissions on symmetrical vertical curve sections.

Table 7 also shows that the radius value of the symmetrical vertical curve has no effect on the carbon emission rate.

The tested carbon emission data of 19 test cases on the asymmetric vertical curve sections are shown in Table 8 . The maximum relative error of the predicted and measured carbon emission data is $9.83 \%$.

Tables 6-8 show that the proposed model has high reliability. The carbon emission rate data of the five test vehicles follow the same rule: the carbon emission rate of vehicles on the vertical curve section is determined by the terminal gradients regardless of the radius. Cumulative carbon emissions are determined by the carbon emission rate and driving distance. The mileage of the vertical profile section remains unchanged. The carbon emissions of car I on the vertical profile sections composed of various forms of vertical curves are given in Table 9 as an example. The maximum relative errors of the tested and predicted $\mathrm{cu}-$ mulative carbon emissions in this case are $8.37 \%$.

The field test data confirm that the quantitative $\mathrm{CO}_{2}$ emission model on vertical curve and vertical profile sections is valid, as is the vehicle $\mathrm{CO}_{2}$ emission rules on various forms of vertical curve sections.

To further explore the distribution trends and dispersion degrees of the simulation results, a descriptive statistical test was performed on the residual values, as shown in Figure 8 and Table 10.

Figure 8 (a) shows that the distribution of residuals basically conforms to the normal distribution. Figure $8(\mathrm{~b})$ shows that the residuals are randomly arranged above and below a straight line passing through the zero point and that they have equal variances. As shown in Table 10, the absolute value of kurtosis is less than 10 and the absolute value of skewness is less than 3 [33]. The descriptive statistical test results indicate that the model residuals follow a normal distribution.

\subsection{Vertical Curve Indexes and Carbon Emissions on Vertical} Profile. The actual vertical profile section is a combination of longitudinal slopes and vertical curves. The effects of radius on the carbon emissions of vehicles on the vertical profile section were also determined in this study followed by a 


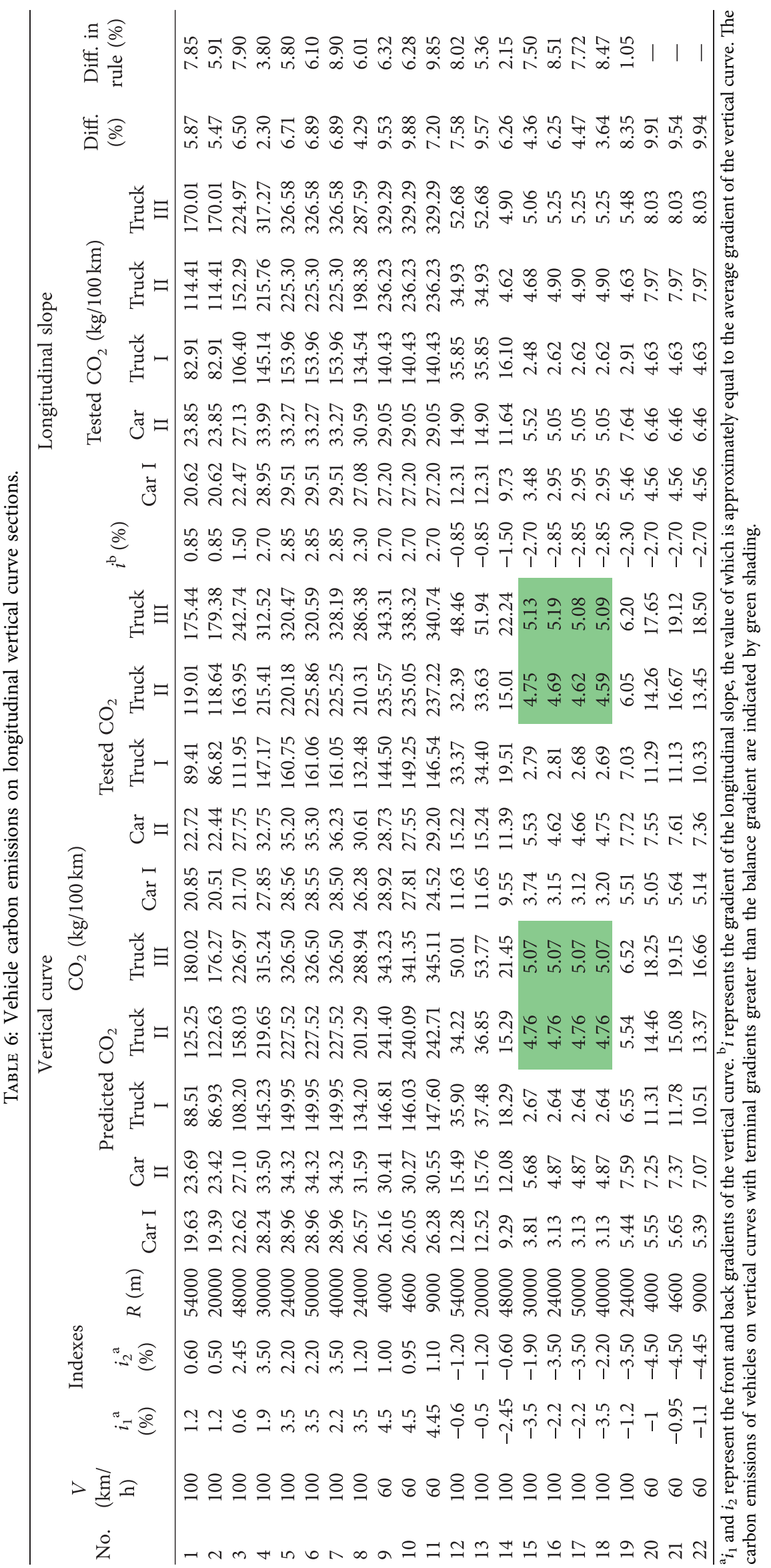


TABLE 7: Vehicle's carbon emissions on symmetrical vertical curve sections.

\begin{tabular}{|c|c|c|c|c|c|c|c|c|c|c|c|c|c|c|c|c|c|}
\hline \multirow{2}{*}{ No. } & \multirow{2}{*}{$\begin{array}{c}v \\
(\mathrm{~km} / \\
\mathrm{h})\end{array}$} & \multicolumn{3}{|c|}{ Indexes } & \multicolumn{5}{|c|}{ Predicted $\mathrm{CO}_{2}(\mathrm{~kg} / 100 \mathrm{~km})$} & \multicolumn{5}{|c|}{ Tested $\mathrm{CO}_{2}(\mathrm{~kg} / 100 \mathrm{~km})$} & \multirow{2}{*}{$\begin{array}{l}\text { Diff. } \\
(\%)\end{array}$} & \multicolumn{2}{|c|}{$\begin{array}{c}\text { Diff. in rule } \\
(\%)\end{array}$} \\
\hline & & $i_{1}(\%)$ & $i_{2}(\%)$ & $R(\mathrm{~m})$ & Car I & $\begin{array}{c}\text { Car } \\
\text { II }\end{array}$ & $\begin{array}{c}\text { Truck } \\
\text { I }\end{array}$ & $\begin{array}{c}\text { Truck } \\
\text { II }\end{array}$ & $\begin{array}{c}\text { Truck } \\
\text { III } \\
\end{array}$ & Car I & $\begin{array}{c}\text { Car } \\
\text { II }\end{array}$ & $\begin{array}{c}\text { Truck } \\
\text { I }\end{array}$ & $\begin{array}{c}\text { Truck } \\
\text { II }\end{array}$ & $\begin{array}{c}\text { Truck } \\
\text { III }\end{array}$ & & Cars & Trucks \\
\hline 1 & 100 & 1.5 & -1.5 & 16000 & 16.59 & 20.39 & 64.26 & 81.44 & 117.62 & 16.55 & 20.55 & 64.31 & 78.81 & 113.86 & 3.33 & 7.31 & 6.65 \\
\hline 2 & 100 & 1.5 & -1.5 & 24000 & 16.59 & 20.39 & 64.26 & 81.44 & 117.62 & 16.62 & 21.22 & 62.43 & 77.64 & 115.92 & 4.89 & 5.96 & 6.61 \\
\hline 3 & 100 & 2.5 & -2.5 & 25000 & 16.59 & 20.39 & 65.20 & 87.08 & 125.16 & 16.45 & 20.70 & 66.54 & 87.10 & 120.85 & 3.56 & 6.63 & - \\
\hline 4 & 100 & 3 & -3 & 17000 & 16.59 & 20.39 & 67.13 & 91.76 & 131.74 & 16.70 & 20.20 & 68.27 & 91.80 & 127.41 & 3.39 & 8.88 & - \\
\hline 5 & 60 & 1.5 & -1.5 & 16000 & 17.58 & 21.22 & 74.98 & 109.34 & 155.39 & 16.05 & 21.32 & 73.11 & 109.34 & 150.84 & 9.51 & 3.89 & 8.10 \\
\hline 6 & 60 & 1.5 & -1.5 & 24000 & 17.58 & 21.22 & 74.98 & 109.34 & 155.39 & 17.51 & 21.00 & 73.01 & 109.03 & 152.49 & 2.70 & 4.85 & 8.22 \\
\hline 7 & 60 & 2 & -2 & 15000 & 17.58 & 21.22 & 74.98 & 109.36 & 155.41 & 16.05 & 21.02 & 76.18 & 108.52 & 165.32 & 9.51 & 3.89 & 6.77 \\
\hline 8 & 60 & 2 & -2 & 20000 & 17.58 & 21.22 & 74.98 & 109.36 & 155.41 & 16.80 & 22.81 & 74.34 & 108.52 & 145.13 & 7.08 & 9.82 & 6.54 \\
\hline 9 & 60 & -4 & 4.05 & 1750 & 17.88 & 21.50 & 81.83 & 124.56 & 176.76 & 19.56 & 22.70 & 87.78 & 123.76 & 175.18 & 8.59 & - & - \\
\hline 10 & 60 & -3.95 & 4 & 4600 & 17.86 & 21.48 & 81.56 & 124.06 & 176.05 & 18.48 & 23.66 & 88.33 & 124.10 & 173.29 & 9.22 & - & - \\
\hline 11 & 60 & 5 & -5 & 1500 & 18.34 & 21.96 & 86.98 & 133.99 & 190.19 & 19.95 & 23.11 & 93.00 & 134.05 & 180.57 & 8.06 & - & - \\
\hline 12 & 60 & 5.1 & -5.08 & 5000 & 18.44 & 22.07 & 87.78 & 135.36 & 192.14 & 19.85 & 23.21 & 89.08 & 135.42 & 196.44 & 7.08 & - & - \\
\hline
\end{tabular}

The carbon emissions of vehicles on the vertical curve with the terminal gradients greater than the balance gradient are indicated by green shading.

TABLE 8: Vehicle's carbon emissions on asymmetric vertical curve sections.

\begin{tabular}{|c|c|c|c|c|c|c|c|c|c|c|c|c|c|c|c|}
\hline \multirow{2}{*}{ No. } & \multirow{2}{*}{$v(\mathrm{~km} / \mathrm{h})$} & \multicolumn{3}{|c|}{ Indexes } & \multicolumn{5}{|c|}{ Predicted $\mathrm{CO}_{2}(\mathrm{~kg} / 100 \mathrm{~km})$} & \multicolumn{5}{|c|}{ Tested $\mathrm{CO}_{2}(\mathrm{~kg} / 100 \mathrm{~km})$} & \multirow{2}{*}{ Diff. (\%) } \\
\hline & & $i_{1}(\%)$ & $i_{2}(\%)$ & $R(\mathrm{~m})$ & Car I & Car II & Truck I & Truck II & Truck III & Car I & Car II & Truck I & Truck II & Truck III & \\
\hline 1 & 100 & 0.8 & -1.40 & 13000 & 15.15 & 18.76 & 54.81 & 65.69 & 95.08 & 14.82 & 19.49 & 56.94 & 62.41 & 96.66 & 5.26 \\
\hline 2 & 100 & 1.4 & -0.80 & 13000 & 18.02 & 22.03 & 73.72 & 97.16 & 140.15 & 16.62 & 24.22 & 69.86 & 92.43 & 136.12 & 9.05 \\
\hline 3 & 100 & 1.476 & -1.64 & 13000 & 16.20 & 19.95 & 61.68 & 77.39 & 111.70 & 15.61 & 21.55 & 59.50 & 78.04 & 108.65 & 7.44 \\
\hline 4 & 100 & 1.64 & -1.48 & 13000 & 16.98 & 20.84 & 66.85 & 85.73 & 123.78 & 16.24 & 19.16 & 65.83 & 90.93 & 122.60 & 8.77 \\
\hline 5 & 100 & 1.5 & -0.76 & 16000 & 18.36 & 22.41 & 75.92 & 100.83 & 145.41 & 17.42 & 21.44 & 77.69 & 98.47 & 140.60 & 5.40 \\
\hline 6 & 100 & 0.76 & -1.50 & 16000 & 14.82 & 18.38 & 52.60 & 62.04 & 89.82 & 15.51 & 16.89 & 54.35 & 59.88 & 84.99 & 8.80 \\
\hline 7 & 100 & 1.7 & -1.54 & 16000 & 16.97 & 20.83 & 66.78 & 85.67 & 123.65 & 18.41 & 22.65 & 65.46 & 83.70 & 121.21 & 8.04 \\
\hline 8 & 100 & 1.54 & -1.70 & 16000 & 16.21 & 19.96 & 61.74 & 77.69 & 112.08 & 15.63 & 21.75 & 58.88 & 79.11 & 109.36 & 8.24 \\
\hline 9 & 100 & -2.2 & 0.80 & 10000 & 13.24 & 16.58 & 42.52 & 49.48 & 71.20 & 14.65 & 15.75 & 46.47 & 46.04 & 74.57 & 9.63 \\
\hline 10 & 100 & -0.8 & 2.20 & 10000 & 19.94 & 24.21 & 86.32 & 118.14 & 170.20 & 21.63 & 22.92 & 80.31 & 112.21 & 172.73 & 7.82 \\
\hline 11 & 100 & 2.44 & -1.40 & 12000 & 19.08 & 23.23 & 80.65 & 108.70 & 156.68 & 18.38 & 21.43 & 74.64 & 101.05 & 158.81 & 8.39 \\
\hline 12 & 100 & 1.4 & -2.44 & 12000 & 14.10 & 17.56 & 48.84 & 60.69 & 87.23 & 12.95 & 18.53 & 46.91 & 59.30 & 86.91 & 8.89 \\
\hline 13 & 100 & -1.93 & 2.85 & 12000 & 18.79 & 22.90 & 78.76 & 106.75 & 153.64 & 18.47 & 22.66 & 76.85 & 108.10 & 153.05 & 2.48 \\
\hline 14 & 100 & -2.85 & 1.93 & 12000 & 14.39 & 17.88 & 52.40 & 67.87 & 97.42 & 13.83 & 16.97 & 52.46 & 70.88 & 102.58 & 5.39 \\
\hline 15 & 100 & 3.2 & -1.40 & 12000 & 20.90 & 25.30 & 92.62 & 128.62 & 185.23 & 23.13 & 26.67 & 85.08 & 123.81 & 183.09 & 9.66 \\
\hline 16 & 100 & 1.4 & -3.20 & 12000 & 12.28 & 15.49 & 41.20 & 51.45 & 73.65 & 11.61 & 14.52 & 39.20 & 52.10 & 76.84 & 6.65 \\
\hline 17 & 60 & -2.2 & 4.00 & 4800 & 21.88 & 26.13 & 103.34 & 156.84 & 223.35 & 20.16 & 27.99 & 99.52 & 153.41 & 214.47 & 8.55 \\
\hline 18 & 60 & -5 & 2.50 & 1500 & 12.61 & 15.39 & 51.59 & 76.66 & 107.89 & 11.55 & 16.46 & 48.74 & 71.04 & 109.04 & 9.21 \\
\hline 19 & 60 & 6 & -3.20 & 2000 & 24.28 & 28.85 & 120.67 & 187.33 & 266.87 & 22.55 & 29.01 & 109.87 & 181.19 & 252.71 & 9.83 \\
\hline
\end{tabular}

sensitivity analysis of vertical curve design indexes on carbon emissions. The indexes studied here include the gradient and radius.

3.2.1. Effect of Radius on Carbon Emissions. The vertical profile was divided into six cases by the balance gradient for analysis, as illustrated in Figure 9. The design specification for highway alignment in China [32] recommends a general radius of $1500 \mathrm{~m}$ for the design speed of $60 \mathrm{~km} / \mathrm{h}$.

The carbon emissions of car I on the vertical profile sections of cases I-VI were obtained using the proposed carbon emission model, as shown in Figure 10.

As shown in Figure 10(a), the carbon emissions of vehicles are independent of radius in cases I-III and V.
When vehicles travel along the uphill vertical profile sections of cases I-II, the carbon emission rate is equal to that on the longitudinal slope section with the average gradient regardless of the radius. The radius has no effect on the height difference to be overcome on the uphill vertical profile. The mileage of the vertical profile section is fixed. Therefore, the cumulative carbon emissions remain unchanged. The same rule emerges in uphill vertical profile sections with terminal gradients larger than the balance gradient.

In case III, the vehicles always require some amount of driving force to traverse downhill vertical profiles with gradients at any point less than the balance gradient, again regardless of the radius. The carbon emission rate and cumulative carbon emissions are independent of the radius and equal to those on the longitudinal slope with the average gradient. 
TABLE 9: Cumulative carbon emissions of car I on vertical curve and vertical profile sections.

\begin{tabular}{|c|c|c|c|c|c|c|c|c|c|c|c|c|c|c|}
\hline \multirow{3}{*}{ No. } & \multirow{3}{*}{$v(\mathrm{~km} / \mathrm{h})$} & \multirow{2}{*}{\multicolumn{4}{|c|}{ Indicators }} & \multicolumn{4}{|c|}{$\begin{array}{l}\text { Cumulative predicted } \mathrm{CO}_{2} \text { emissions } \\
\qquad(\mathrm{g})\end{array}$} & \multicolumn{4}{|c|}{ Cumulative tested $\mathrm{CO}_{2}$ emissions $(\mathrm{g})$} & \multirow{3}{*}{ Diff. (\%) } \\
\hline & & & & & & \multicolumn{2}{|c|}{ Vertical curve } & \multicolumn{2}{|c|}{ Vertical profile } & \multicolumn{2}{|c|}{ Vertical curve } & \multicolumn{2}{|c|}{ Vertical profile } & \\
\hline & & (\%) & $l_{2}(\%)$ & $K(\mathrm{~m})$ & & Forward & Reverse & Forward & Reverse & Forward & Reverse & Forward & Reverse & \\
\hline 1 & 100 & 1.2 & 0.6 & 54000 & 530 & 64.38 & 40.29 & 104.02 & 65.10 & 63.27 & 38.31 & 106.37 & 62.77 & 5.16 \\
\hline 2 & 100 & 1.2 & 0.5 & 20000 & 530 & 27.14 & 17.53 & 102.75 & 66.37 & 28.25 & 16.65 & 105.86 & 69.43 & 5.29 \\
\hline 3 & 100 & 3.5 & 2.2 & 24000 & 850 & 90.35 & 9.76 & 246.14 & 29.62 & 89.75 & 9.86 & 245.09 & 30.05 & 1.42 \\
\hline 4 & 100 & 3.5 & 2.2 & 50000 & 850 & 188.23 & 20.33 & 246.14 & 27.72 & 179.06 & 21.93 & 242.41 & 26.53 & 7.29 \\
\hline 5 & 60 & 4.5 & 1 & 4000 & 500 & 36.63 & 7.77 & 130.82 & 34.76 & 38.68 & 7.45 & 134.50 & 32.98 & 5.41 \\
\hline 6 & 60 & 4.5 & 0.95 & 4600 & 500 & 42.53 & 9.23 & 130.23 & 34.88 & 40.69 & 9.21 & 132.41 & 35.61 & 4.53 \\
\hline 7 & 60 & 4.45 & 1.1 & 9000 & 500 & 79.25 & 16.26 & 131.42 & 30.66 & 80.54 & 15.50 & 136.11 & 29.11 & 5.34 \\
\hline 8 & 100 & 2 & -2 & 16000 & 1160 & 106.17 & 106.17 & 192.44 & 192.44 & 99.77 & 100.14 & 182.66 & 182.66 & 6.42 \\
\hline 9 & 100 & 2 & -2 & 24000 & 1160 & 159.26 & 159.26 & 192.44 & 192.44 & 151.15 & 152.08 & 193.98 & 191.98 & 5.36 \\
\hline 10 & 60 & 2 & -2 & 16000 & 1160 & 112.49 & 112.49 & 203.88 & 203.88 & 107.09 & 108.54 & 200.08 & 189.18 & 7.77 \\
\hline 11 & 60 & 2 & -2 & 24000 & 1160 & 168.73 & 168.73 & 203.88 & 203.88 & 156.14 & 156.28 & 208.41 & 189.82 & 8.06 \\
\hline 12 & 60 & 5 & -5 & 1500 & 710 & 27.51 & 27.51 & 149.90 & 149.90 & 26.54 & 28.53 & 141.39 & 138.08 & 8.56 \\
\hline 13 & 60 & 5.1 & -5.08 & 5000 & 710 & 93.88 & 93.48 & 138.29 & 137.80 & 87.14 & 89.11 & 135.77 & 129.85 & 7.74 \\
\hline 14 & 60 & 6 & -5.88 & 2000 & 800 & 45.85 & 44.80 & 182.22 & 179.55 & 45.04 & 45.28 & 174.13 & 170.45 & 5.34 \\
\hline 15 & 60 & 6.01 & -6 & 5000 & 800 & 114.99 & 114.77 & 163.41 & 163.14 & 115.60 & 114.09 & 159.13 & 153.50 & 6.28 \\
\hline 16 & 60 & -4 & 4.05 & 1750 & 565 & 25.19 & 24.89 & 108.24 & 107.43 & 24.05 & 23.10 & 100.11 & 100.57 & 8.12 \\
\hline 17 & 60 & -3.95 & 4 & 4600 & 565 & 65.31 & 64.52 & 104.10 & 103.07 & 60.27 & 62.04 & 96.76 & 97.15 & 8.37 \\
\hline
\end{tabular}

${ }^{\mathrm{c}} L_{\mathrm{vp}}$ indicates the distance of vertical profile $(m)$.

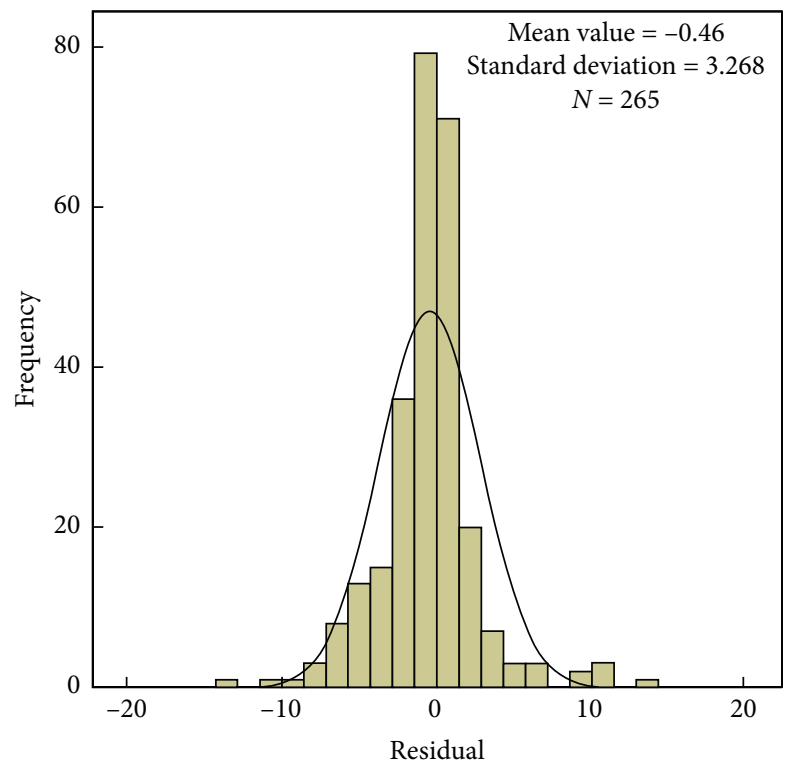

(a)

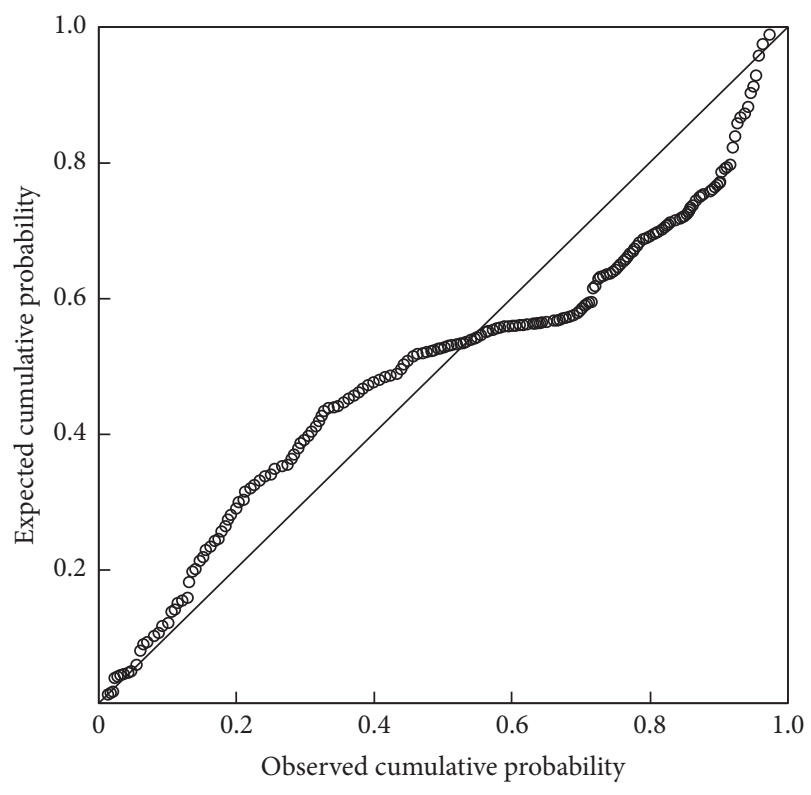

(b)

Figure 8: Normal distribution test of model residuals: (a) histogram; (b) P-P plot.

TABle 10: Parameters of descriptive statistics test.

\begin{tabular}{lcccccc}
\hline Minimum & Maximum & Mean & Variance & Standard deviation & Skewness & Kurtosis \\
\hline-14.16 & 15.77 & -0.46 & 10.682 & 3.268 & 0.753 & 5.676 \\
\hline
\end{tabular}

When the gradients at both ends of the symmetrical vertical curve are not greater than the balance gradient (case $\mathrm{V}$ ), the carbon emission rate is equal to that on the flat section regardless of the radius. The extracarbon emissions on the uphill section appear to offset the reduced carbon emissions on the downhill section as compared with the flat sections. The cumulative carbon emissions on the symmetrical vertical curve are the same as those on the equal-mileage flat section.

In case IV, the downhill vertical profile has one terminal gradient greater than the balance gradient while the other is 


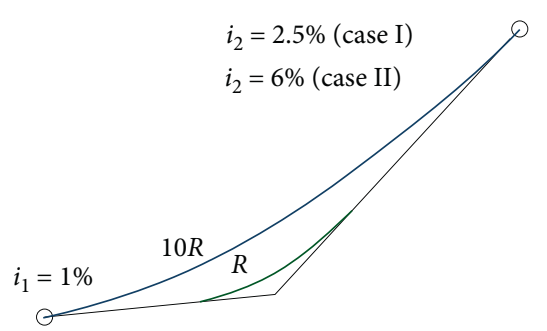

(a)

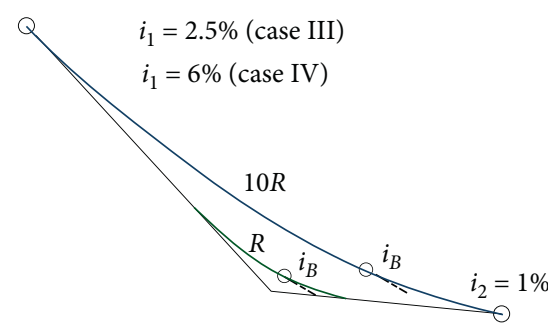

(b)

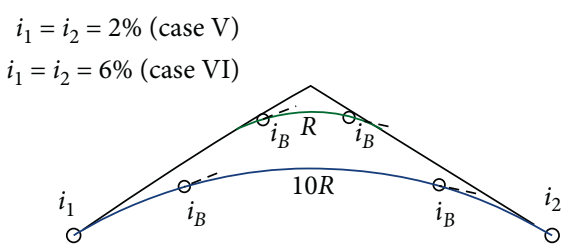

(c)

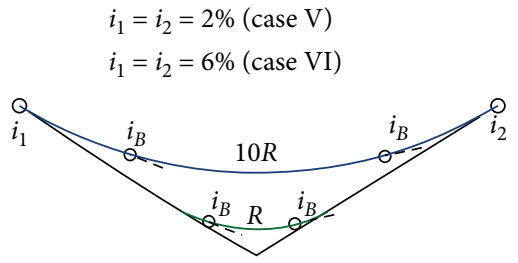

(d)

FIGURE 9: Six cases vertical curves in vertical profile: (a) uphill vertical curve; (b) downhill vertical curve; (c) symmetrical crest vertical curve; (d) symmetrical sag vertical curve.

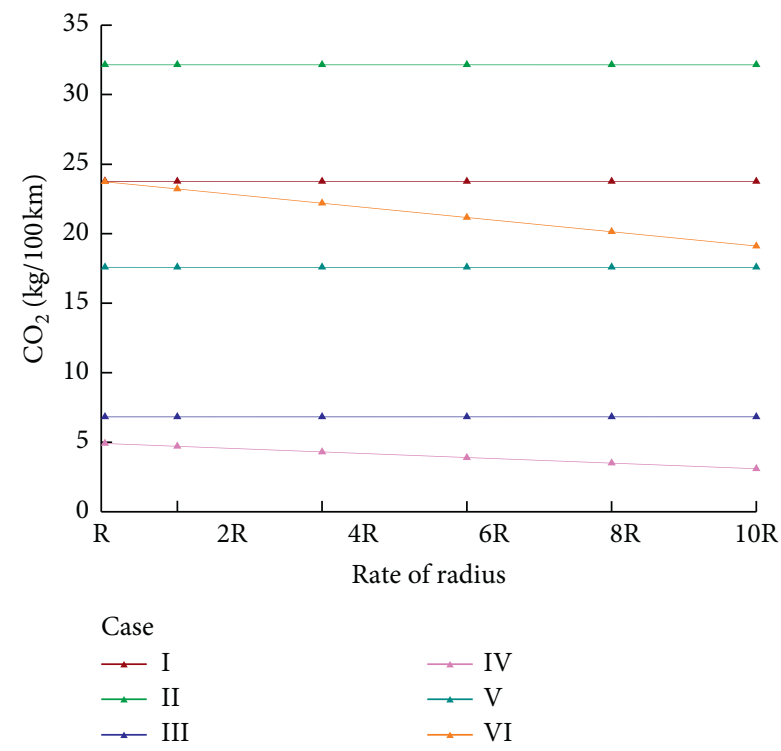

(a)

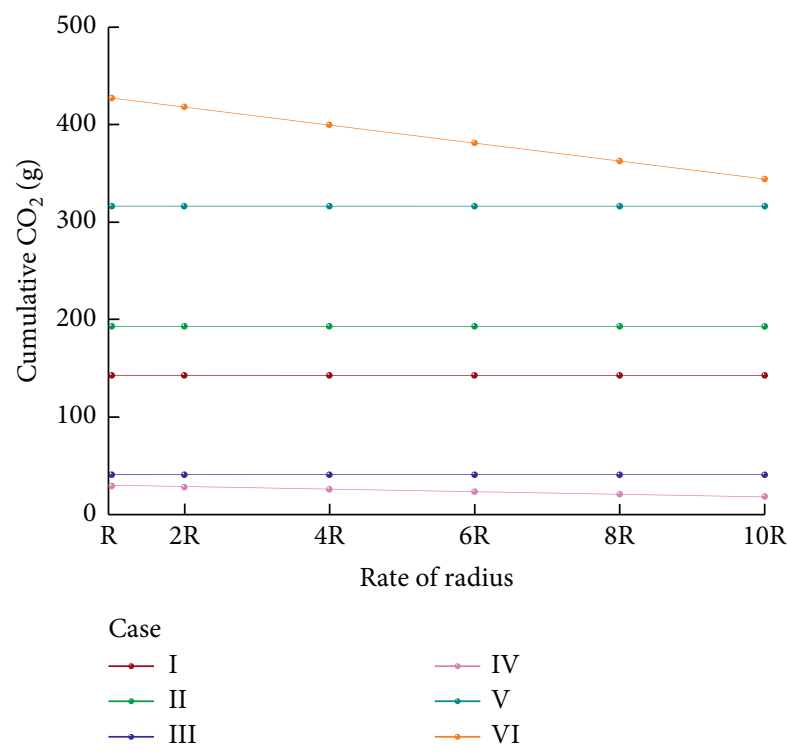

(b)

Figure 10: Vehicle carbon emissions on vertical profile sections of cases I-VI: (a) carbon emission rate; (b) cumulative carbon emissions.

not. The cumulative carbon emissions in this case can be obtained by the following equations:

$$
\begin{aligned}
& \mathrm{CO}_{2(R)}=C_{V} R\left(i_{2}-i_{1}\right)+C_{i} R\left(i_{2}-i_{1}\right) \frac{(n-1)}{2}, \\
& \mathrm{CO}_{2(n R)}=C_{V} n R\left(i_{2}-i_{1}\right),
\end{aligned}
$$

where $\mathrm{CO}_{2(R)}$ and $\mathrm{CO}_{2(n R)}$ are the cumulative carbon emissions of a vehicle on the vertical curve with a radius of $R$ and $n R$, respectively. $C_{v}$ is the carbon emission rate of a vehicle on the vertical curve, and $C_{i}$ is the carbon emission rate of a vehicle on the back longitudinal slope.

According to equation (31), when $i_{1}+i_{2}>2 i_{B}, C_{i}>2 C_{v}$. The length of the back longitudinal slope decreases as the radius increases. Equations (55)-(56) also indicate that a larger $R$ reduces the mileage of the downhill section where the vehicle needs driving force, thereby reducing its cumulative carbon emissions.

In case VI, the terminal gradients of symmetrical vertical profile are greater than the balance gradient, and the 
cumulative carbon emissions can be obtained according to the following equations:

$$
\begin{aligned}
& \mathrm{CO}_{2(R)}=2 C_{V} R_{i}+C_{i} R_{i}(n-1), \\
& \mathrm{CO}_{2(n R)}=2 C_{V} n R_{i} .
\end{aligned}
$$

The extracarbon emission rates on the uphill section were greater than the reduced carbon emission rates on the downhill section. According to equation (49), $C_{i}>2 C_{v}$ when $i>i_{E}$. The length of the uphill section with the gradient greater than the balance gradient decreases as the radius increases. This reduces the gravitational potential energy to be overcome on the uphill slope. The symmetrical vertical profile in case VI, which was designed with a greater radius, is conducive to the reduction of carbon emissions. This is consistent with the results presented by Ko et al. [1]

A larger radius results in less cumulative carbon emissions on the downhill vertical profile in case IV and on the symmetrical vertical profile in case VI. The same rules were found to apply for asymmetric vertical curve sections with gradients larger than the balance gradient. The radius is irrelevant to the carbon emissions on the other forms of vertical profile.

When a vertical curve is designed with a general radius higher than the standard, it necessitates extra construction costs for the earthwork for curve flattening [34]. The earthwork volumes in the test area were determined here using the average area method under the assumptions that the width of a two-lane highway was $7 \mathrm{~m}$ and the cut side slopes were $1: 1.5$. The driving conditions on the two-way traffic lanes differ in case IV, so only the lane of the vertical profile section in the downhill direction was analyzed here. The flattened-curvature design appears to reduce vehicle engine loads and consequently reduced fuel consumptions during the trips in terms of fuel costs. The annual average daily traffic on the vertical profile sections under cases IV and VI was assumed to be $5000 \mathrm{pcu} / \mathrm{d}$; traffic volumes for the passenger cars and medium trucks accounted for $90 \%$ and $10 \%$ of the total, respectively. Emission reductions from these curve designs may be beneficial in terms of societal and public health. The economic benefits from the carbon emission reductions were monetized with unit values of 148.50 RMB per metric ton in 2019 [35].

The Shaanxi Provincial Department of Transportation provided relevant data in 2020 for Shaanxi Province, China: the average cost of one cubic meter of earthwork equals 7.4 RMB, and the average unit prices of gasoline and diesel are 5.41 RMB and 5.02 RMB, respectively; the average annual growth rate of passenger cars is 3\%. Table 11 lists the estimated benefits and costs on vertical profile sections with the above-designed curves in cases IV and VI accordingly. The expected benefits and costs during design periods were adjusted to 2019 dollars with a $3 \%$ discount rate for societal and public health costs and a $7 \%$ discount rate for fuel costs [36]. The benefits generated by the curve-flattening design are greater than the costs under cases IV and VI for 16-year and 13-year design periods, respectively.
On the downhill vertical profile in case IV, symmetrical vertical profile in case VI, and asymmetric vertical profile with the gradient larger than the balance gradient, the flattened-curvature vertical curve design is beneficial to the environment and economy throughout the life cycle of the expressway.

3.2.2. Sensitivity Analysis. The radius affects the vehicle's carbon emission rate on the vertical profile in cases IV and VI. A schematic diagram of the sensitivity analysis results for the gradient and radius under cases IV and VI is shown in Figure 11; the carbon emission rate of car I was obtained from the proposed carbon emission model.

In case IV, as radius increases by $10 \%$ from $1500 \mathrm{~m}$ to $3000 \mathrm{~m}$, the carbon emission rate decreases by $24.68 \%$. In case VI, as the radius increases by $10 \%$ from $1500 \mathrm{~m}$ to $3000 \mathrm{~m}$, the carbon emission rate decreases by $11.81 \%$. In case IV, as the front gradient increases by $10 \%$ from $-6 \%$ to $0 \%$, the carbon emission rate increases by $212.34 \%$. This is consistent with the rule of equation (36). In case VI, as the front gradient increases from $-6 \%$ to $0 \%$ by $10 \%$, the carbon emissions rate decreases by $18.95 \%$. This trend is consistent with equation (53).

Figure 11 shows that the influence of gradient on vehicle carbon emissions across vertical profile sections in cases IV and VI is more significant than that of the radius.

3.3. Discussion. This paper proposes a carbon emission model for vehicles on vertical curve sections based on Xu's energy conversion model on longitudinal slopes $[9,10]$ and the IPCC conversion model [24]. Compared with the existing carbon emission model, the model proposed has a more sufficiently theoretical basis and is applicable to directly predict the carbon emissions of vehicles on vertical curve sections under the current status of China. Ko et al. [1] used MOVES to predict the carbon emissions on a symmetrical vertical curve section with the terminal gradients greater than the balance gradient. The larger the radius is, the less the carbon emissions are produced. This is consistent with the results of this study. Specifically, the larger the radius, the less the carbon emission rate in this scenario. The carbon emission model proposed reveals that the basic reason is the mileage where additional driving fuel and braking energy losses is reduced. It also shows that the gradient has a greater influence on the carbon emission rate than the radius in this scenario.

This study centers on the carbon emissions of vehicles on vertical curve sections. The horizontal alignment was required to be straight or with a radius greater than $2000 \mathrm{~m}$ during the field test, which eliminated the influence of horizontal alignment on vehicle carbon emissions. The influence of vertical curve design indicators on the carbon emissions of common passenger cars and trucks was explored here where the vehicle was assumed to travel at a cruising speed, thus eliminating the influence of velocity fluctuations on carbon emissions. The quantitative carbon emission model has limited ability to forecast the carbon emissions of vehicles on vertical curve sections when 
TABLE 11: Estimated benefits and costs on vertical profile sections.

\begin{tabular}{lcccc}
\hline Case & Extra construction cost (RMB) & Fuel cost saving (RMB) & Health cost saving (RMB) & \multicolumn{2}{c}{ Benefit-cost ratio } \\
& & & 3.12 & years \\
16 years
\end{tabular}

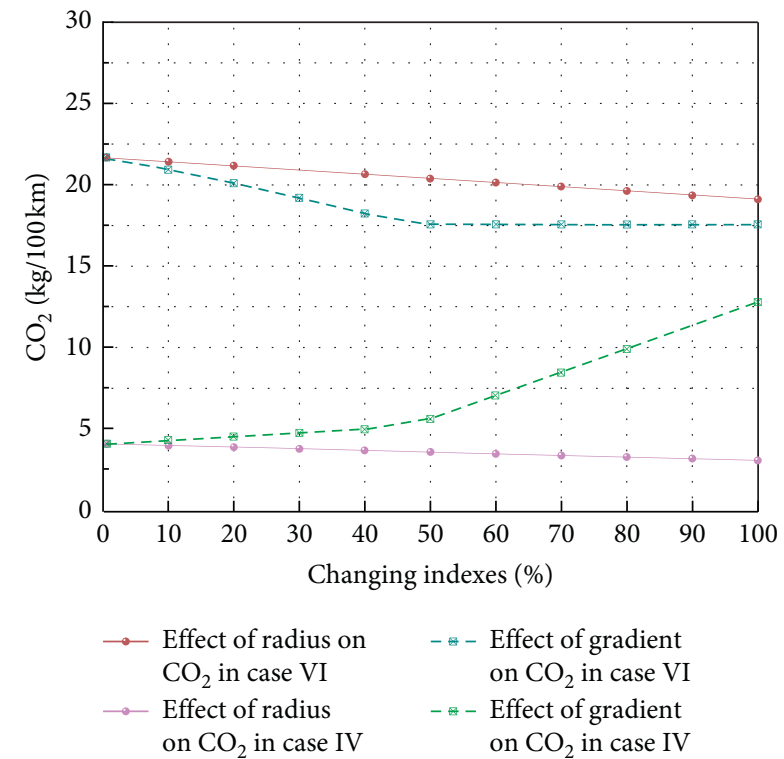

Figure 11: Passenger car carbon emission trends under changing indexes.

fluctuating in speed during travel. The propulsive energy of a vehicle with fluctuating speed is closely related to its inertial resistance during acceleration and the characteristics of its engine gearbox [18]. These factors should be considered in future studies to more accurately estimate real-world driving conditions.

Five typical vehicles comprising majority of highway traffic in China were selected as the test vehicles in this study. Different regions have different fuel characteristics, vehicle performance, road pavement types, and pavement conditions. The model presented here can be modified by adjusting certain parameters (e.g., vehicle type, engine type, fuel type, road condition, vehicle load, frontal area, and tire type) for application of other types of fuel-powered vehicles in other regions. Mechanical efficiency and fuel utilization rates were also idealized here, which may have had some impact on the results.

\section{Conclusion}

The model proposed in this paper was shown to accurately quantify the fuel consumption and carbon emissions of vehicles on vertical curve sections in China. The carbon emission rules on different forms of vertical curves as well as the influence of vertical curve indicators (gradient and radius) on carbon emissions were determined. The results can reduce the uncertainty in engineering judgments for environmentally friendly highway vertical profile designs. The main findings can be summarized as follows:

(1) The vehicle's carbon emission rate on the vertical curve is independent of the radius, as well as the crest or sag form of the vertical curve. The carbon emission rate of vehicle on the vertical curve is determined by the difference between the terminal gradients of the vertical curve and balance gradient.

(2) When a vehicle traverses a vertical curve with an uphill trend, the height difference that the vehicle needs to overcome is fixed; the carbon emission rate is equal to that on the longitudinal slope with the average gradient. When the terminal gradients of the downhill vertical curve are both less than the balance gradient, driving energy is required during the travel, and the carbon emission rate is determined by the terminal gradients. When a vehicle travels downhill on a vertical curve with one of the terminal gradients greater than the balance gradient, braking is necessary at certain road sections to maintain the cruise speed; the vehicle's carbon emission rate is thus determined by terminal gradients and balance gradient. When the terminal gradients of the downhill vertical curve are greater than the balance gradient, vehicle can slide downhill in the gear position and the carbon emission rate is equal to that during idling.

(3) When the gradients at both ends of the symmetrical vertical curve are less than the balance gradient, the carbon emission rate of the vehicle is almost equal to that on the flat road section; the uphill and downhill sections balance each other. When the terminal gradients of the symmetrical vertical curve are greater than the balance gradient, the carbon emission rate is greater than that on flat sections. More driving energy is needed on the upward curve segment where the gradient is greater than the balance gradient to offset the braking energy loss during downhill driving. The greater the carbon emission rate increases as the terminal gradients increase.

(4) On the vertical profile composed of downhill/ asymmetric/symmetrical vertical curves and with a gradient greater than the balance gradient, the carbon emission rate is determined by the gradients and radius. A larger radius results in a smaller carbon emission rate because the mileage and driving force are reduced on downhill sections with gradients less than the balance gradient and on uphill sections with gradients greater than the balance gradient. The 
radius has less impact on the carbon emission rate of vehicles on these vertical profile sections than the terminal gradients of the vertical curve. The radius is irrelevant to the carbon emission rate on other forms of vertical profile.

(5) The gradient should be kept below the balance gradient in the vertical profile design to conserve energy and minimize carbon emissions from twoway traffic. If the gradient requirements cannot be met due to terrain restrictions or other reasons, the radii of the downhill vertical curve, symmetrical vertical curve, and asymmetric vertical curve should be increased to reduce carbon emissions.

\section{Data Availability}

The data used to support the findings of this study are available from the corresponding author upon request.

\section{Conflicts of Interest}

The authors declare that there are no conflicts of interest regarding the publication of this paper.

\section{Authors' Contributions}

Y.D. and J.X. prepared methodology for the study. Y.D. and J.X. validated the study. Y.D. did formal analysis. Y.D. and J.X. curated the data. J.X. investigated the study. Y.D. reviewed and edited the manuscript and wrote the original draft. J.X. helped in obtaining funding acquisition, administrated the project, supervised the study, and visualized the study.

\section{Acknowledgments}

The authors are grateful to the Shaanxi Provincial Department of Transportation for generously providing relevant information and the highway design documents of the test road sections. We also thank the drivers for their cooperation during the field experiment. This research was funded in part by the National Key Research and Development Program of China (no. 2016YFC0802208) and the Transport Technology Project of Shaanxi Province (Grant no. 18-23R).

\section{References}

[1] M. Ko, D. Lord, and J. Zietsman, Environmentally Conscious Highway Design for Crest Vertical Curves, Transportation Research Record Journal of the Transportation Research Board, Washington, DC, USA, 2012.

[2] H. Guo, Q.-y. Zhang, Y. Shi, and D.-h. Wang, "Evaluation of the International Vehicle Emission (IVE) model with on-road remote sensing measurements," Journal of Environmental Sciences, vol. 19, no. 7, pp. 818-826, 2007.

[3] H. Abou-Senna, E. Radwan, K. Westerlund, and C. D. Cooper, "Using a traffic simulation model (VISSIM) with an emissions model (MOVES) to predict emissions from vehicles on a limited-access highway," Journal of the Air \& Waste Management Association, vol. 63, no. 7, pp. 819-831, 2013.
[4] M.-W. Kang, S. Shariat, and M. K. Jha, "New highway geometric design methods for minimizing vehicular fuel consumption and improving safety," Transportation Research Part C: Emerging Technologies, vol. 31, pp. 99-111, 2013.

[5] M. Barth, F. An, T. Younglove et al., NCHRP Web-Only Document 122: The Development of a Comprehensive Modal Emissions Model; Final Report, Transportation Research Board of the National Academies, Washington, DC, USA, 2008.

[6] D. J. Chang and E. K. Morlok, "Vehicle speed profiles to minimize work and fuel consumption," Journal of Transportation Engineering, vol. 131, no. 3, pp. 173-182, 2005.

[7] W. Harrington, V. D. Mcconnell, and M. Cannon, "A behavioral analysis of EPA's mobile emission factor model," Discussion Paper, Resources for the Future, EPA, Washington DC, USA, 1998, https://ageconsearch.umn.edu/record/10676/

[8] M. Ehsani, A. Ahmadi, and D. Fadai, "Modeling of vehicle fuel consumption and carbon dioxide emission in road transport," Renewable and Sustainable Energy Reviews, vol. 53, pp. 1638-1648, 2016.

[9] J. Xu, Y. Dong, and M. Yan, “A model for estimating passenger-car carbon emissions that accounts for uphill, downhill and flat roads," Sustainability, vol. 12, no. 5, p. 2028, 2020.

[10] Y. P. Dong, J. L. Xu, and C. W. Gu, "Modelling carbon emissions of diesel trucks on longitudinal slope sections in China," PLoS One, vol. 15, no. 6, Article ID e0234789, 2020.

[11] E. Demir, T. Bektaş, and G. Laporte, "A comparative analysis of several vehicle emission models for road freight transportation," Transportation Research Part D: Transport and Environment, vol. 16, no. 5, pp. 347-357, 2011.

[12] IPCC (Intergovernmental Panel on Climate Change), "Guidelines for national greenhouse gas inventories," in Prepared by the National Greenhouse Gas Inventories Program, H. S. Egglestone, L. Buendia, K. Miwa et al., Eds., Vol. 2, IGES, Tsukuba, Japan, 2006.

[13] Y. Dong, J. Xu, X. Liu, C. Gao, H. Ru, and Z. Duan, "Carbon emissions and expressway traffic flow patterns in China," Sustainability, vol. 11, no. 10, p. 2824, 2019.

[14] Y. Dong, J. Xu, M. Li, X. Jia, and C. Sun, "Association of carbon emissions and circular curve in northwestern China," Sustainability, vol. 11, no. 4, p. 1156, 2019.

[15] S. Park and H. Rakha, "Energy and environmental impacts of roadway grades," Transportation Research Record: Journal of the Transportation Research Board, vol. 1987, no. 1, pp. 148160, 2006.

[16] T. D. Rakha, Fundamentals of Vehicle Dynamics, Society of Automotive Engineers, Tokyo, Japan, 1992.

[17] D. Crolla and B. Mashadi, Vehicle Powertrain Systems Wiley, John Wiley \& Sons, New York, NY, USA, 2012.

[18] J. Y. Wong, Theory of Ground Vehicles, John Wiley \& Sons, New York, NY, USA, 4th edition, 2008.

[19] M. Yan and J. Xu, "Prediction model for brake-drum temperature of large trucks on consecutive mountain downgrade routes based on energy conservation law," Mathematical Problems in Engineering, vol. 2018, Article ID 4587673, 10 pages, 2018.

[20] W. Hucho and G. Sovran, "Aerodynamics of road vehicles," Annual Review of Fluid Mechanics, vol. 25, no. 1, pp. 485-537, 1993.

[21] H. Rakha, I. Lucic, S. H. Demarchi, J. R. Setti, and M. V. Aerde, "Vehicle dynamics model for predicting 
maximum truck acceleration levels," Journal of Transportation Engineering, vol. 127, no. 5, pp. 418-425, 2001.

[22] J. W. Fitch, Motor Truck Engineering Handbook, Society of Automotive Engineers, Warrendale, PA, USA, 4th edition, 1994.

[23] Society of Automotive Engineers (SAE), Commercial Truck and Bus SAE Recommended Procedure for Vehicle Performance Prediction and Charting, SAE Procedure J2188, Warrendale, PA, USA, 1996.

[24] IPCC (Intergovernmental Panel on Climate Change), "Climate Change 2007" the Fourth IPCC Assessment Report, IPCC (Intergovernmental Panel on Climate Change), Geneva, Switzerland, 2007.

[25] F. Ruzzenenti and R. Basosi, "Evaluation of the energy efficiency evolution in the European road freight transport sector," Energy Policy, vol. 37, no. 10, pp. 4079-4085, 2009.

[26] China Environmental Science Press, Limits and Measurement Methods for Emissions from Light-Duty Vehicles (GB 18352.52013), China Environmental Science Press, Beijing, China, 2018.

[27] Ministry of Energy of the People's Republic of China, Gasoline for Motor Vehicles (GB 17930-2016), China Standard Press, Beijing, China, 2016.

[28] Ministry of energy of the people's Republic of China, Diesel for Motor Vehicles (GB 19147-2016), China Standard Press, Beijing, China, 2016.

[29] National Development and Reform Commission, Department of Climate Change, Land Transport Companies' Greenhouse Gas Emissions Accounting Methods and Reporting Guidelines (Trial), NDRC, Beijing, China, 2015, http://www.ndrc.gov.cn/ zcfb/zcfbtz/201511/W020151111537500754764.pdf.

[30] National Development and Reform Commission, Climate Change Division, Second National Communications on Climate Change in the People's Republic of China, China Economic Publishing House, Beijing, China, 2013.

[31] Chinese Government, The first two-year update Report on climate change in the people's Republic of China, Chinese Government, Beijing, China, 2019, http://www.webcitation. org/75mAIC7ah.

[32] China Standard Press, Design Specification for Highway Alignment (JTG B01-2017), China Standard Press, Beijing, China, 2017.

[33] R. M. Vogel, "The probability plot correlation coefficient test for the normal, lognormal, and Gumbel Distributional Hypotheses," Water Resources Research, vol. 23, no. 10, p. 2013, 1987.

[34] L. Amara, B. Youssef, and R. Hesham, "Use of life cycle cost analysis and multiple criteria decision aid tools for designing road vertical profiles," Sustainability, vol. 11, no. 24, p. 7127, 2019.

[35] B. Mark, Atlanta congestion reduction demonstration. National Evaluation: Cost Benefit Analysis Test Plan, 2011.

[36] NHTSA (National Highway Traffic Safety Administration), Greenhouse Gas Emissions and Fuel Efficiency Standards for Medium- and Heavy-Duty Engines and Vehicles-Phase 2, NHTSA (National Highway Traffic Safety Administration), Washington, DC, USA, 2016. 